University of San Diego

Digital USD

1990

\title{
The Impact of Federal Regulation on Time to Equivalence and Compliance within the Orthopaedic Medical Device Industry
}

John J. Carlow EdD

University of San Diego

Follow this and additional works at: https://digital.sandiego.edu/dissertations

Part of the Leadership Studies Commons

\section{Digital USD Citation}

Carlow, John J. EdD, "The Impact of Federal Regulation on Time to Equivalence and Compliance within the Orthopaedic Medical Device Industry" (1990). Dissertations. 540.

https://digital.sandiego.edu/dissertations/540

This Dissertation: Open Access is brought to you for free and open access by the Theses and Dissertations at Digital USD. It has been accepted for inclusion in Dissertations by an authorized administrator of Digital USD. For more information, please contact digital@sandiego.edu. 
TIRP IMTEACT OP FEDGRAC RBGULATION ON TIMB TO BQUTVALETCE

AND CCMPLIANCE WITHIN THB ORTHOPARDIC MEDICAT DEVICB INDOSTRY

by

John J Carlow

A dissertation submitted in partial fulfillment

of the requirements of the degree of

Doctor of Education

University of San Diego

1990

Dissertation Committee

Susan Zgliczynski, Ph.D., Director

Jerome Ammer, Ph.D. Joyce Bromm; R.N., J.D. 


\section{ABSTRACT \\ The Impact of Federal Regulation on Time to Equivalence \\ and Complience within the Orthopaecic Medicai Device Industry}

The Medica' Device Amendments of 1976 (Public Law 94-295) consolidated and expanded existing federal authority over manufacturers of medical devices. This meant that any medical device manufactured after the Medical Device Amendment of 1976 needed to establish that it is substantially equivalent in terms of content, composition, intended use and related risk. This study was designed to investigate the influences on the process of notifying the Food and Drug Administration (FDA) of an orthopaedic medical device manufacturer's intent to market a product. The study's primary objectives were iworoin: is determine the relationships of three independent variables (i.e., the company's size and lorgevity) with the dependent variable, time to equivalence and 2) compare differences in mean days to equivalence based on specified company characteristics (i.e., regulatory affairs consultant use, regulatory training experiences, in-house regulatory department presence or absence, and attitudes toward influences on timely compliance). A survey instrument was returned by the regulatory manager at 39 companies representing 263 device equivalence submissions and 27 different medical device categories from 1977 through 1987. Four different statistical approaches were utilized: correlative-regressive, comparative, regressive-predictive, and distributive. From thiis research certain company characteristics which impact time to equivalence were idertified. It was found that companies who have been manufacturing numercus years, manufacture more than one medical device, and use regulatory affairs professionals to assist with compliance issues, especially just following the enactiment of a new regulation, may have predictakly fewer days to equivalence than companies that do not possess these characteristics. Statistically significant relationships and differences in mean days to equivalence were computed for some variables. 


\section{DEDICATION}

This research is dedicated to my parents for all they have given me and to my son for all I will be able to give him. 


\section{ACKNOWLEDGEMENTS}

I would like to express special gratitude to Dr. Susan zgliczynski, my Committee Chairperson, for her guidance, encouragement, and patience in the executiurs of tinis research endeavor. A very special thought goes out to Dr. Dee Strunk, my first Committee Chairperson, who has passed away.

A grateful acknowledgement is made to Dr. Jerry Ammer and Ms. Joyce Bromm, Esq., for their intellectual stimulation and encouragement.

I would also like to express my thanks to Ms. Pamela Buckman, my sister and employer, for her help, encouragement, support, and trust.

Finally, I would like to acknowledge my family and friends for their patience, sacrifices, and tolerance during the period of my studies. 
Page

DEDICATION

ACKNOWLEDGEMENTS iii

IIST OF FIGURES. vii

LIST OF TABLES viii

LIST OF ÄPPEITICES.

CHAPTER I.

INTRODUCTION .

Statement of Problem.................. 3

Research question Number $1 \ldots \ldots \ldots \ldots \ldots . . . .7$

Research Question Number 2.......... 8

Research Question vumber $3 \ldots \ldots . . \ldots . . .9$

Research Question Number 4........... 11

Research Question Number $5 \ldots \ldots \ldots \ldots \ldots . \ldots 11$

Importance and Relevance............... 11

Research Assumptions and Limitations........ 13

Yethodological Tradeoffs................. 14

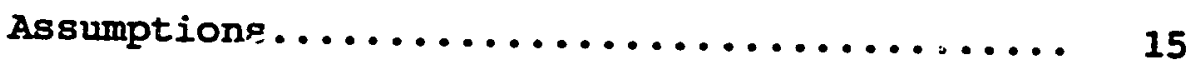

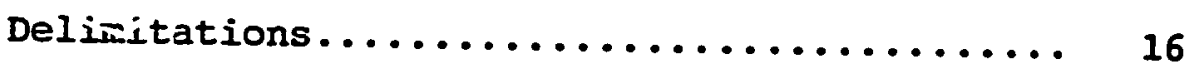

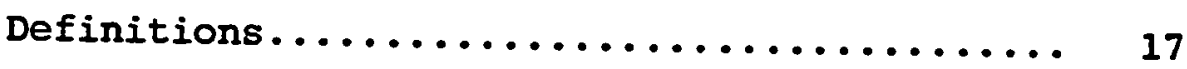

Summary .......................... is

CHAPTER II. REVIEW OF THE IITERATURE......... 20

Historical Dimension.................. 20

Sccial Regulation................ 20

Social Regulation and the

Medical Device Industzy......... 23

iv 
Page

Regulated Industry Studies.............. 30

Research studies..................... 32

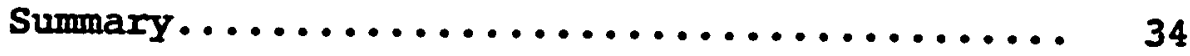

CHAPTER III. METHODOLOGY................ 36

Introduction...................... 36

Choice of Method.................... 37

Research Population................... 42

Instrumentation..................... 43

Pilot study....................... 46

Procedures.......................... 48

Questionnaire Mailing.............. 48

Data Collection and Follow-Up........ 50

Research Approach and Data Analysis........ 52

Approach $1 \ldots \ldots \ldots \ldots \ldots \ldots \ldots \ldots \ldots \ldots \ldots$

Approach II.................... 53

Approach III..................... 54

Approach IV..................... 54

Criteria for Data Sources............... 55

summary ................................. 56

CHAPTER IV. DATA ANALYSIS.............. 57

Unit of Analysis.................... 58

Medical Device Categories.............. 59

Results of Analysis.................. 61

Research Question Number $1 \ldots \ldots \ldots \ldots \ldots \ldots$

Research question Number $2 \ldots \ldots \ldots \ldots \ldots 71$

$\checkmark$ 
Page

Research Question Number 3.......... 85

Research Question Number $4 \ldots \ldots \ldots \ldots \ldots$...... 98

Research Question Number 5.......... 103

Sumary............................ 106

CHAPTER V. SUMMARY AND RECOMMENDATIONS....... 113

Summary........................... 113

The Research Problem............... 113

The Research Apprcaches............. 114

Criteria for Data Sources............ 115

Review of Selected Literature......... 116

Method....................... 117

Collection of Data................ 118

Analysis of Data................ IIz

Findings......................... 119

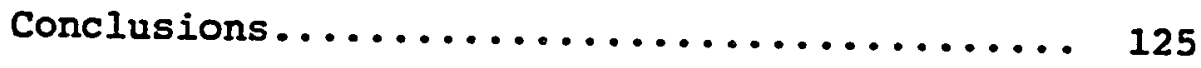

Implications for Business and Government.... 129

Recommendations for Future Research........ 132

REFERENCES. ............................. 135

APPENDICES.............................. 145

Appendix A.......................... 145

Appendix B......................... 146

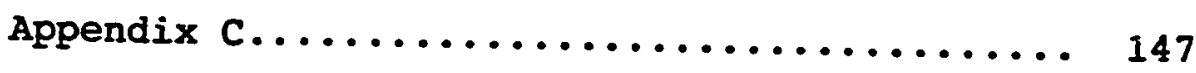

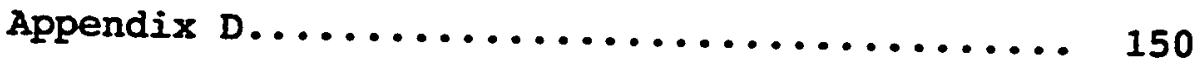

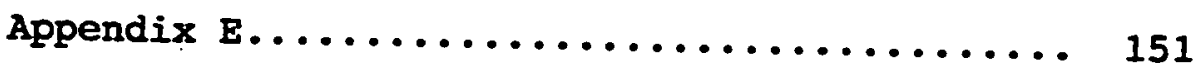

Appendix F........................ 152

vi 


\section{LIST OF FIGURES}

Figure

Page

1. Orthopaedic Device Classification Category and FDA Device Classification............ 49

2. Orthopaedic Medical Device Category, Number of Companies, and Number of Device

Submissions per Device Category...

vii 


\section{IIST OF TABLES}

Table

Page

1. Model Relating Variable DAYS TO EQUIVALENCE to Variable NUMBER OF YEARS MRNUFACTURING....

2. Quadratic Model Relating Variable DAYS TO EQUIVAIENCE to Variable NUMBER OF YEAR

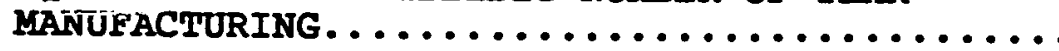

3. Model Relating Variable DAYS TO EQUIVALENCE to Variable NUMBER OF EMPLOYEES IN THE ORGANIZATION.

4. Model Relating Variable DAYS TO EOUIVALENCE to Variable NUMBER OF EMPLOYEES IN

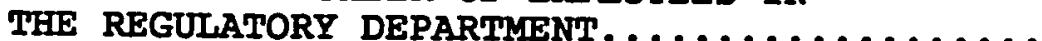

5. Wilcoxon Score (Rank Sums) for Variable DAYS TO EQUIVALENCE Classified by

Variable TYPE OF DEVICE...............

6. Wilcoxon Score (Rank Sums) for Variable DAYS TO EQUIVALENCE Classified by Variable REGULATORY DEPARTMENT.

7. Wilcoxon Score (Rank Sums) for Variable DAYS TO EQUIVALENCE Classified by

Variable REGULATORY TRAINIYG.............

8. Wilcoxon Score (Rank Sums) for Variable DAYS TO EQUIVALENCE Classified by Variable

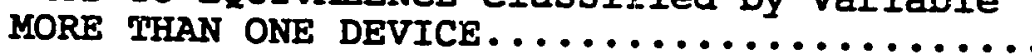

9. Wilcoxon Score (Rank Sums) for Variable DAYS TO EQUIVALENCE Classified by Variable

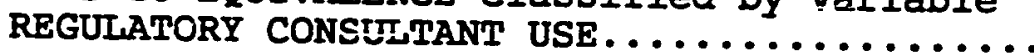

10. Wilcoxon Score (Rank Sums) for Variable DAYS TO EQUIVALENCE Classified by Variabie ATTITUDE TOWARD WRITTEN COMMUNICATION

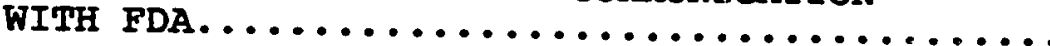

11. Wilcoxon Score (Rank Sums) for Variable DAYS TO EQUIVALENCE Classified by Variable ATTITUDE TOWARD ORAI COMMUNICATION WITH FDA..

12. Wilcoxon Score (Rank Sums) for Variable DAFS TO EQUIVALENCE Classified by Variable ATTITUDE TOWARD REGULATORY TRAINING........ viii 
13. Crosstabulation of Variable DAYS TO EQUIVALENCE by Variable ATTIPUEA TOAñ

REGULATORY TRAINING.

14. Wilcoxon Score (Rank Sums) for Variable

DAYS TO EQUIVALENCE Classified by Variable

ATTITUDE TOWARD IÑ-HOÜSE REGULATORY

DEPARTMENT

15. Wilcoxon Score (Rank Sums) for Variable DAYS TO EQJIVALENCE Classified by Variable ATTITUDE TOWARD REGULATORY CONSULTANT USE...

16. Crosstabulation of Variable DAYS TO

TO EQUIVALENCE by Variable ATTITUDE TOWARD

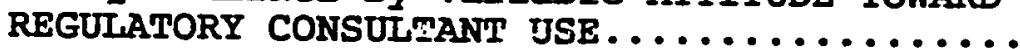

17. Model Relating Variable DAYS TO EQUIVALENCE to Multiple Independent Variables.......... 100

18. Frequency Distribution of Entities Impacting Variable DAYS TO EQUIVALENCE............. 105 


\section{IIST OF APPENDIXES}

Appendix

Page

A. Transmittal Letter for Pilot Study.......... 145

B. Transmittal Letter for Research............ 146

C. Survey questionnaire................... 147

D. Sumary of Research Eypotheses 1.1 - 1.3:

Relationships Between Organizational

Characteristics and Time to Equivalence...... 150

E. Summary of Research Eypotheses 2.1 - 2.5:

Differences in Time to Equivalence Relative

to Organizational Characteristics.......... 151

F. Summary of Research Bypotheses $3.1-3.5=$

Differences in Time to Equivalence Relative to Top Executive's Perceived Influences on

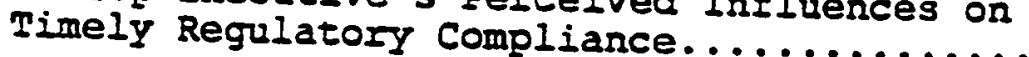


(.HAPTER I

\section{INTRŨニTCTION}

What do Band-Aids, contact lenses, cardiac pacemakers, and magnetic resonance imaging machines have in common? They are all medical devices, according to federal law. Judging the safety and effectiveness of these four products and over 47,000 other medical devices is the job of the Food and Drug Administration (FDA). But for a variety of reasons, federal regulation of medical devices is beset with major problems. As a result, little information is available to determine whether medical devices, which are becoming increasingly sophisticated, are safe and work as intended.

The situation above has Iorced the $F D$ to reverse the present congressional sentiment of deregulation and, sonsequentiy, impose more controls upon medical device manufacturers. The number of device establishments has exploded to more than 12,0j0 and every one is jockeying for market position. Government requirements are a hurdle to new products and better sales.

This study proposes to evaluate the relationships and differences between regulatory requirements and time to established equivalence or FDA disposition in the orthopaedic medical device industry. The concentration in the orthopaedic area in the medical device industry was guided by concerns regarding the narrowing of 
research focus and significance of ultimate research findings. More specifically, the process of interpreting regulatory requirements and timely submissions in the orthopaedic medical device area is the primary aim of this research. The paradigm, "Time is money!", is assentially being examined. The longer a developed product remains off the market, the greater the consumption of the manufacturer's resources and dccreased share of market.

The degree of market share protection a company can expect depends on the rouce chosen by the company to market its product. One route is the section 510(k) (Public Law No. 94-295); or the premarket notification process (PMAA), of the Federal Food, Drug, and Cosmetic Act (FDC Act) (Public Law No. 75-717). Under section $510(k)$, a manufacturer is required to file with FDA a premarket notification at least ninety days before marketing a class I or class II device. The purpose of the $510(\mathrm{k})$ is to establish that the device is substantially equivalent to another device already on the market. A $510(\mathrm{k})$ notification is generally a few pages long and usually does not contain clinical data. The FDA's average review time for the $510(k)$ is approximately 64 days (FDA Annual Report, 1988). Although FDA has 90 days to complete the review process, the manufacturex must wait for either 90 days or until it is notified by FDA of the device's equivalence.

The PMAA process is the second route to market. The content requirements for a PMAA are much more rigorous than the 
requirements for the $510(k)$ notification process. A PMAA is a voluminous and detailed submission that usually includes preclinical and clinical data. The average review time for a PMAA is 142 to 262 days (FDA Annual Report, iš8).

The scope of this research is limited to gathering data as it relates to the $510(\mathrm{k})$ process only.

The $510(K)$ Reqister (Diogenes, 1988) is a document which has been published annually since 1976. This is the year in which regulatory reform was introduced to the medical device industry. All $510(k) s$ filed since 1976 are listed in this document. From this text can be gleaned the submission dates and the dates when equivalence was determined. These days can vani from as few as two days to as many as 200 or more. Estimated costs are associated with each day that product does not reach equivalence and ultimately the market. These days are reduced or enhanced by the manufacturer's ability to interpret regulations, comply with those regulations, and establish substantial equivalence to a product which was on the market prior to 1976 .

THE PROBLEM

Statement of Problem

The Medical Device Amendments of 1976 (Public Law 94-295) consolidated and expanded existing federal authority over medical devices. It enacted a system of regulating safety and effectiveness

Page 3 
of medical devices in proportion to the degree of risk they posed. This meant that any medical device manufactured arter the Medical Device Amendment of 1976 needed to establish that it was substantially equivalent in terms of content, composition, intended use and related risk. If this equivalency was established, FDA required nothing more than pre-market notification. If found not to be equivalent, other more rigorous requirements were imposed (e.g., multi-centered clinical trials). Conducting multi-centered clinical trials was very expensive and resource intensive. Even if equivalence could be escablished, delays, due to misinterpretation of guidelines, inability to provide required information, etc., in securing the FDA's disposition could also incur additional expenses.

The task of implementing some of the key provisions and managing the cost of some provisions relative to the incramental gains in safety and effectiveness have placed considerable burdens on the medical device industry. Regardless of efforts by FDA to streamline the approval process, Drew (1986) emphasized that many of the large firms and a majority of the small firms were at the leading edge of science and technology, but had relatively little knowledge and experience in meeting regulatory requirements. This situation might only slightly delay the marketing of a product or might result, in the most extreme case, in the demise of an organization. The purpose of this study was to assess the impact 
of regulatory compliance on time to equivalence in the orthopaedic medical device industry.

The data gathered regarding the dependent variable, time to equivalence (days) and product characteristics was obtained from a document referenced in the Introduction section of this paper, The $510(\mathrm{k})$ Reqister. This annually published document provided the following information: product classification, product type, sponsor or manufacturer's name, submission date, and date of substantial equivalence. It also listed the number of requests by FDA for further information before disposition was reached, and elapsed days from time of siomission to time of equivalence.

The predictor or independent variables, $x$, were: number of years manufacturing medical devices, organizational size, and regulatory department size, if present.

One-way analysis of variance was performed to assess the difference in organizational characteristics and time to equivalence. The criterion or dependent variable was measured in time (days) to equivalence.

The independent variables were discrete dichotomies and ordinal levels of measurement. Those variables included the following: the type of medical device manufactured, the presence or absence of an in-house regulatory department, regulatory training experience, number of medical devices manufactured, use of out-of-house regulatory consultants, attitude toward written 
communication with FDA, attitude toward oral communication with FDA, attitude toward regulatory training, attitude toward the presence of an in-house regulatory department, attitude toward the nse of out-of-house regulatory consultants, and production costs.

As indicated above, Research Question Number 2 and Hypotheses 2.1 listed below entailed evaluation of the type of medical device manufactured. This classification scheme developed by FDA was explicated in the Definitions section of this document. A device was classified as class I, II, or III based upon the degree of risk regarding safety and effectiveness of the device and its complexity. Oxthopaedic device classification I would include simple device types which pose minimal risk to the patient (e.g., bandage, cast, forceps, etc.). classification III would include devices which present a significant risk, such as, shoulder prosthesis or artisicial heart.

Further analysis entailed the investigation of the combined influence of independent variables which best predicted time to equivalence.

All analyses were stratified by the years 1977 through 1987.

If distribution imbalances were observed, nonparametric toois were imposed.

Prognostic information was retrieved via mailed questionnaires, phone interviews, and personal interviews. The questionnaire enclosed in Appendix $C$ served as the data collection 
Time To Equivalence

vehicle.

N1l hypotheses were stated in the null.

oltimately, this study was designed to investigate the fnfiuences on the process of notifying FDA of an orthopaedic medical device manufacturer's intent to market a product which was substantially equivalent to a device manufactured prior to the 1976 Medical Device Amendments.

Research Questions

\section{Research Question Number 1}

What is the relationship between time devoted to establishing an FDA dispcsition of substantial equivalence for an orthopaedic medical device and related costs and resource consumption?

Eypothesis 1.1. There is no relationship between time (days) needed to establish equivalence and the number of years a company has been manufacturing medical devices. This hypothesis relates to question numbez I sin the questionnaire. Hypothes is 1.2. There is no relationship between time (days) needed to establish equivalence and the number of employees in an organization. This hypothesis relates to question number 2 on the questionnaire

Hypothesis 1.3. There is no relationship between time (days) needed to establish equivalence and the number of employees in the regulatory department. This hypothesis relates to question number 2 on the questionnaire.

Page 7 


\section{Research Question Number 2}

Is there any difference between respondents (companies) who possess or do not possess certain identified characteristics and time required to establish equivalence?

Hypothesis 2.1. There is no difference between the type of medical device manufactured and time to equivalence. This hypothesis relates to information secured from the $510(\mathrm{k})$ Register.

Hypothesis 2.2. There is no difference between companies having in-house regulatory departments and companies that don't have in-house regulatory departments on time to equivalence. This hypothesis relates to question number 2 on the questionnaire.

Hypothesis 2.3. There is no difference between companies who received regulatory compliance training and companies who didn't receive regulatory compliance training on time to equivalence. This hypothesis relates to question number 3 on the questionnaire.

Eypothesis 2.4. There is no difference between companies who manufacture one medical device and companies that manufacture more than one device on time to equivalence. This hypothesis relates to question number 3 on the questionnaire. 
Time To Equivalence

Hypothesis 2.5. There is no difference between companies who report using regulatory affairs consultants and companies that don't use regulatory affairs consultants on time to equivalence. This hypothesis relates to question number 2 on the questionnaire.

\section{Research Question Number 3}

Is there any difference between time to equivalence and respondent's (company's) attitudes about selected characteristics of the regulatory process as having an impact on time to equivalence?

Hypothesis 3.1. There is no difference between the companies who perceive FDA written communication as hiaving an impact on timely compliance and companies that don't perceive FDA written communication as having an impact oñ timely compliance on time to equivalence. This hypothesis relates to question number 5 on the questionnaire.

Hypothesis 3.2. There is no difference between companies who perceive FDA oral communication as having an impact on timely compliance and companies that don't perceive FDA oral communication as having an impact on timely compliance on time to equivalence. This hypothesis relates to question number 6 on the questionnaire. 
Hypothesis 3.3. There is no difference between companies who perceive the Office of Small Manufacturers Assistance (OSMA) regulatory compliance training as having an impact on timely compliance and companies who don't perceive the OSMA regulatory compliance training as having an impact on timely compliance on time to equivalence. This hypothesis relates to question number 7 on the questionnaire.

Hypothesis 3.4. There is no difference between companies who perceive having an in-house regulatory department as having an impact on timely compliance and companies who don't perceive having an in-house regulatory department as having an impact on timely compliance on time to equivalence. This hypothesis relates to question number 8 on the questionnaire. Hypothesis 3.5. There is no difference between companies who perceive the use of outside regulatory affairs consultants as having an impact on timeiy compiiance and companies that don't perceive the use of outside regulatory affairs consultants as having an impact on timely compliance on time to equivalence. This hypothesis relates to question number $g$ on the questionnaire 


\section{Research Question Number 4}

What combination of indepencent rariable mearures best predicts time to equivalence? This research question takes information from all the questions on the questionnaire.

\section{Research Question Number 5}

What variables appear to have an impact on time to equivalence as perceived by the company respondent? This research question relates to questions number 4 and 10 on the qutiotionnaire.

\section{Importance and Relevance}

Numerous changes in FDA regulations over the past ten years have created a dynamic environment for firms in the medical device industry. Although the overall picture for the medical device industry was optimistic and growing, the repercussions of the 1976 legislation presented serious problems. Cost of compliance, FDA expectations, FDA dispositions, and device reclassifications all placed a strain on individual firm resources and management. Any effort to conserve resources and reduce costs while maintaining market position was viewed as cost effective and beneficial to management in medical device enterprises.

Specifically, compliance with federal regulations and related strategic adaptation in relation to resource allocation and cost reduction in the medical device industry had not been directly 
investigated in the past. Financial survival and industry leadership may directly be linked with regulatory compliance. of importance might be the investigation of the relationship between regulatory dispositions and medical device corporate short/long term planning in response to regulatory agencies requirements. Does a pattern exist in which predictable elements emerge which, with some high probability, contribute to reduced days in securing FDA disposition (equivalence) regarding a product?

It would be of value if a manager could anticipate with some reilability the approximate number of days it would take for that product to Ieací equivaience once a $510(\mathrm{k})$ had been submitted to FDA. With this knowledge there could be some planning alterations in terms of marketing, sales, and production strategies.

Assuming the federal social regulations inherent in the FDA guidelines were in accordance with the degree of risk associated with the device and that these guidelines did provide an adequate audit trail which, if followed, were cost accountable at the very least, the regulatory department manager or corresponding responsible individual could and should benefit from being well versed in the avenues essential to reaching equivalence.

One of the major decisions related to the cost of the equivalence process was the use of in-house versus out-of-house regulatory professionals. 
Management must be able to weigh certain variables to determine when it was cost effective to bring in outside consultants to assist in the interpretation of device related guidelines. There were multiple factors for the chief executive to take into account when considering whether to use in-house or outside regulatory professionals. When evaluating available resources and possible costs in establishing equivalence not only on one device at one point in time, but equivalence for numerous devices ovex years, a chief executive might consider the following possibilities: expanding the responsibilities of present employees, developing a new department (Regulatory Affairs), and/or hiring more employees for the new department. If a regulatory department was already in-house, the chief executive may need to hire more employees to meet the increased demands, or enlist the assistance of regulatory consultants outside of the firm. This study evaluated the above implied variables and associated patterns.

Research Assumptions and Limitations

To gain a greater understanding of the limitations of this research, it was necessary to extend the review to key methodological characteristics. In order to do so, three aspects of the research design were examined - 1) data source, 2) measurement of profitability, and 3) data analysis. 
The different types of measurement procedures employed in operationalizing a construct played a critical role in determining the validity of the results. These procsdures (e.g., content analysis, quantitative calcuiation, investigator inference) translated data sources (e.g., questionnaire, publicly available $510(k)$ Register) into specific types of measures (e.g., retrospective nominal and ordinal scales, trend lines).

Data analysis referred to whether the type of anclysis employed was qualitative or quantitative. This characteristic was important for differentiating findings which were primarily useful for theory building from those which were useful to theory testing.

\section{Methodological Tradeoffs}

Miller and Friesen (1982) in reviewing the characteristics of different approaches to longitudinal analysis of organizations, identified three major dimensions along which research tradeoffs were generally made: 1) breadth of focus, i.e., number of variables, 2) sample size and 3) the extent to which quantification occurs. Relative ease in analysis and interpretation were generally achieved at the expense of specification error created by an overly narrow scope, lack of generalizability created by overly small sample size, or lack of reliability due to a non-quantitative analysis approach. 
These shortcomings in turn lead to a body of non-cumulative findings. On the other hand, cumulative findings yere ofter achieved at the expense of a lack of appropriate data and inadequate model construction due to quest for overly broad scope. Data collection tended to be inefficient and over-generalization tended to occur because of an overly large sample size and overdependence on quantitative analysis that ignored the importance of intuition-guiding 'soft data'.

In addition, the existence of nonlinearities and intrasample differences tended to be overlocked. All of these problems lead to findings that were cumulative, but difficult to interpret.

The above highlighted precautions and concerns bring about the following research assumptions and delimitations:

\section{Assumptions}

1. Federal social regulation did impact time to equivalence and related financial profits in orthopaedic medical device firms to a varying degree.

2. The impact of federal social regulation upon time to equivalence could be perceived by top management (Regulatory Âffairs Department Director) of medical device firms.

3. The sampled population was fairly homogeneous when stratified by calendar year. 
4. Profit-making was essential to the purpose of any business in the United States.

5. Respondents to the questionnaire were informed individuals as to impacts of regulations and organizational characteristics.

6. The research design was adequate for the purpose of the research.

7. The analysis of data did not significantly alter relationships among variables and gave an adequate representation of relationships.

8. The data collected were a satisfactory indication of the impact of federal social regulation upon time to equivalence for orthopaedic medical device manufacturers.

\section{Delimitations}

1. The questionnaire was distributed to top-level executives of randomized orthopaedic medical device firms throughout the United States.

2. The research was limited to information willingly supplied by participant firms.

3. The measurement of time to equivalence and related profitability in the orthopaedic medical device field as it relates to federal regulation was a relatively new endeavor. Conclusions based upon findings of the study should not be considered 
Time To Equivalence

appropriate for generalization to areas other than those encompassed by the present study.

4. The role of the researcher was to evaluate the influences of a regulatory process, as well as, determine the dynamics of emergence in the orthopaedic medical device industry. These two motives for exploration could have introduceu some conflicts and bias.

\section{Definitions}

Corporate Social Responsibility: This term referred to compliance measures implemented by a corporation which could alter or adjust product design, development; manufacturing, procurement, or distribution in response to health and safety requirements stipulated through federal social regulation.

Pre-amendiuent Devices: Devices on the market before May 28, 1976, when the Medical Device Amendments were enacted.

Post-amendment Devices: Devices put on the market after May 28, 1976. Unless shown to be substantially equivalent to a device that was on the market before the amendments took effect, these devices are automatically placed in Class III. A manufacturer may petition F̄̄A Ior reclassification.

Substantial Equivalence: Although not defined by law, congressional intent was to ensure fair treatment of post-amendment devices that were similar to gre-amendment devices, as well as limit the number 
of new devices that would require premarketing approval. 510(k) Process: These notifications were the formal notices submiciced to FDA by the medical device inoustry in order to quickly obtain FDA permission to market medical devices.

Time to Equivalence: This defined the time measured in days required by FDA to come a disposition that a device is substantially equivalent to an already approved device or to a device marketed prior to May 28, 1976.

Class I Medical Device: Class I, general controls, encompasses devices for which general controls were sufficient to provide reasonable assurances of safety and effectiveness, i.s.. tongue depressor.

Class II Medical Device: Class II, performance standards, contained devices for which controls were considered insufficient to ensure safety and effectiveness and information existed to establish performance standards, i.e. X-ray devices.

Class III Medical Device: Class III, premarket approval, applied to devices for which general controls were insufficient to ensure safety and efficacy. Information did not exist to establish performance standards and the device supports life, prevents health impairment, or presents a potentially unreasonable risk of illness or injury, i.e. implantable heart valve. 
Office of Small Manufacturers Assistance (OSMA) - This office was included in the 1976 enactment of the Medical Device Amendments to the Food, Drug, and Cosmetic Act. This legislation provided for the establishment of an identifiable office to help small manufacturers of medical devices understand and comply with the new FDA requirements for these products under that law.

\section{Summary}

Regulation of orthopaedic medical device manufacturers was of two basic types: (1) economic regulation aimed at maximizing profits and (2) social regulation aimed at accomplishing social objectives. Both types affected companies who manufacture medical devices to a varying degree.

Research was conducted to determine relationships and differences between federal social regulation, company characteristics, and time to equivalence. Research questions examining the impact of federal social regulation upon time to equivalence for orthopaedic medical device manufacturing firms were stated.

Delineation of questions separated dependent variables, independent variables, and their elements. General linear model and analysis of variance approaches were used as the research method. Criteria for data sources were outlined and definitions of specific terms as used in the study were discussed in this chapter. 
Time To Equivalence

CHAPTER II

\section{REVIEW OF IITERATURE}

This section presented a review of the literature covering aspects of social regulation and the medical device industry. An historical dimension was presented on the interrelationship between government policy and the operation of business firms. This section concluded with an overview of government regulation of medical devices by the Food and Drug Administration.

\section{Historical Dimension}

\section{Social Requlation}

Social regulations have undergone the greatest growth in terms of agencies and expenditure of government funds. Wieidenbaum (1977) identified major expansion in six areas: job safety, traffic safety, consumer product, personnel practice and discrimination in employment, consumer finance, environment and resources. The growth of social regulation has continued extensively. From the period of 1970 to 1977, the number of social regulatory agencies increased from 12 to 17, and expenditures for these agencies rose from $\$ 1,449.3$ million to $\$ 7,318.3$ million (Miller and Yandle, 1979).

In the area of job safety, federal and state governments have passed laws affecting nonunion workers. Included is unemployment 
compensation, minimum wage laws, social security IEws, and safety laws. The Occupational Safety and Health Act (OSHA) of 1970 gave the federal government a tremendous amount of power and authority to set and enforce safety regulations even in the smallest of rirms (Nicholson, Litschert, and Anthony, 1974).

In the area of traffic safety, the NHTSA has actively regulated safety $a t a n d=r d a ~ a f f e c t i n g$ the design of automobiles. For example, regulated safety standards include "uniform bumper heights, damage limitations resulting from $5 \mathrm{mph}$ test crashes, and mandatory seat belts, air bags, or other restraint mechanisms" (Ferreira, 1982).

In the area of consumer products, federal regulatory interest in product safety-related matters has grown enormously. Several new agencies with interests in product safety have been established, including the Consumer Product Safety Commission (CPSC) in 1972. The Consumer Product Safety Act required the maintenance of records to ensure that firms are complying with its provisions and granted the CPSC access to these records (Eads, 1981).

A number of preexisting agencies with product safety responsibilities were strengthened. Among those are the Federal Trade Commission (FTC), the Food and Drug Administration (FDA), and the Department of Agriculture (USDA).

In the area of personnel practice, the Equal Employment Opportunity Commission (EEOC) and OSHA have impacted business 
considerably. An idea proposed by Smith (1981) that would substitute for OSHA regulations would be a $\$ 500$ deductible for every successful worker's compensation claim, with that deductible then paid by the employer. This idea did not include health co.orage.

In the area $f f$ consumer finance, federal credit programs assumed three forms: direct lending by United State's governmentowned agencies, direct lending by privately owned agencies sponso:ad by the federal government to serve public interest, and the insuring or guaranteeing of loans extended directly by private lenders to private borrowers (Swanson, 1974). The immediate function of federal credit agencies was to provide credit accommodation for borrowers generally considered marginal or at least subject to relatively high risk arising from cyclical fluctuations or other special ractors. In a more fundamental sense, as Swanson (1974) put it, these agencies were oriented toward redistributing economic resources for achieving graater economic stability in certain sectors of the economy.

In the area of environmental programs, the Environmental Protection Agency (EPA) contributed greatly. The EPA set emissions standards for power plants based upon the location of each plant, current ambient concentrations of air pollutants, a computer model for the plani's impact upon local air quality, and a consideration of the technology available for controlling the pollutants (Bardach 
and Kagan, 1982). Other regulatory programs, such as the Clean Air Act of 1970, distinguished between old and new facilities and placed less stringent controls upon existing plants. Under the Act and its amendment of 1977, all cars sold in the United States must eventually achieve a 90 percent reduction in carbon monoxide, hydrocarbons, and nitrous oxide emissions from the level of 1970 controls (Bardach and Kagan, 1982).

\section{Social Regulation and the Medical Device Industry}

Medical device regulation was first adhered in the Federal Food, Drug, and Cosmetics Act of 1938. Although this act is best known for requiring pre-market notification for the safety of new drugs, devices also came under its expansive umbrella. The 1938 Act defined medical devices in the Federal Register as:

....instruments, apparatus, and contrivances, including their components, parts and accessories, intended (1) for use in the diagnosis, care, mitigation, treatment, or prevention of disease in man or other animals; or (2) to affect the structure or any function of the body of man or other animals.

mine 1938 act authorized FDA to inspect any site in which devices were manufactured, processed packed, or held. It also 
authorized FDA to seize adulterated or misbranded medical devices. FDA also had the power to request an injunction against their production, distribution, or use; or seek criminal prosecution of the responsible manufacturer or distributor. But the agency could not take action until after a device had been marketed.

In the early regulatory actions taken against adulterated or misbrancied devices, FDA was able to use expert testimony to prove its allegations. Over time, however, FDA increasingly had to test devices suspected of violating the law in order to remove these devices from the market (U.S. Congress House Report No. 94-853).

As medical devices became more complex.after World war II, attention turned to the regulation of legitimate devices as well. But FDA could still act only after devices were distributed and also had the burden of proving that a particular item was misbranded or unsafe, because devices were not subject to premarket approval (AMP, Inc. V. Gardner, 1968).

In the late $1960^{\circ}$, however, the courts ruled that certain products (such as nylon sutures and antibiotic-sensitive discs) that fell in the grey area between drugs and devices could legally be considered drugs and subject to premarket approval requirements for new drugs $(12,302)$. Subsequently, FDA regulated as "new drugs" such products as some intrauterine devices (IUDs), some contact lenses, and some in vitro diagnostic products. 
Furthermore, during the late $1960^{\prime} \mathrm{s}$, Congress addressed public health problems associated with radiation emissions from electronic products. Under the Radiation Control for Health and Safety Act of 1968 (Public Law 90-602), Congress established a radiation control program to authorize the establishment of standards for electronic products, including medical and dental radiology equipment.

From the early 1960's to 1975, six Presidential messages were given and 28 bills were introduced to enact medical device legislation.

A 1969 Department of Health, Education, and Welfare review of the scientific literature for injuries associated with medical devices that was conducted by the cooper comittee (named after its chairman, Theodore Cooper, then Director of the National Heart, Iung, and Blood Institute of the National Institutes of Health) estimated that over a 10-year period, 10,000 injuries were associated with medical devices, of which 731 resulted in death (U.S. Congress House Committee Hearing No. 93-6I).

The vast majority of these problems were associated with three device types: artificial heart valves, 512 deaths and 300 injuries; cardiac pacemakers, 89 deaths and 186 injuries; and intrauterine contraceptive devices, 10 deaths and 8,000 injuries (U.S. Congress House Committee Hearing No. 93-61). As observers noted, however, there had been no sensational event or public tragedy to spur more stringent regulation of medical devices such as the events leading 
to the $196 \%$ Drug Amendment (Igelhart, 1973).

Additional examples of hazards associated with medical devices were documented in congressional hearings in 1973. These included prosthetic and orthopaedic implants of improper materials, cardiac defibrillators with faulty electrical circuitry, incubators in which temperatures reached as high as $145^{\circ} \mathrm{F}$, plastic tracheotomy tubes with obstructions, and faulty valves on emergency oxygen respirators (U.S. Congress House Committee Hearing No. 93-61).

The developments just described eventually culminated in the enactment of the Medical Device Amendments of 1976 (Fublic Iaw sat295)

Today, while public well-being and fraudulent "miracle cures" continue to demand FDA's attention, it is the number and diversity of legitimate medical devices that present the greatest problems in regulation. There are more than 1,700 types of medical derices; the various models and sizes of each type add up to between 40,000 and 50,000 separate products (Drew, 1986). These types of devices range from the simplest (such as tongue depressors) to the most complex (such as magnetic resonance imagers), and from the most routine (such as urine collection bottles) to the most critical and life-preserving (such as artificial hearts).

These medical devices were produced by approximately 8,000 firms, many of them small, relatively new enterprises (Drew, 1986). Over 95 percent had fewer than 500 employees, and half of those had 
Time To Equivalence

\section{fewer than 50 employees.}

Many of these small firms were at the leading edge of science and technology, but had relatively little knowledge and experience in meeting regulatory requirements. Because those requirements depended on the nature of the device, rather than the size of the company producing it, smail firms had to spend a large proportion of their resources for regulatory compliance than larger firms.

Recognizing this situation, FDA established the Division of Small Manufacturers Assistance (DSMA) to help small firms to cope with the regulations.

All medical devices were subject to some level of regulation by FDA, but the nature and the degree of that regulation varies. The more hazardous the device, the greater the regulation. The intent was to protect users and patients, while imposing the least possible regulatory burden on producers of devices.

This was accomplished by classifying medical devices into three groups -- Class I, Class II, Class III --- with the least hazardous devices in Class I and the most hazardous in Class III. The classification of a device determined which regulatory "channel" it follows.

Class I devices, such as adhesive bandages, toothbrushes ana tongue depressors, present risks that can be managed by "general controls". These general controls represented a regulatory baseline, which all manufacturers, importers, and distributors must 
meet. They included registration of the firm with FDA and periodic listing of all medical devices produced or hariled by the firm. Also, whenever a firm intended to introduce a new or significantly modified device to its product line, it had to notify gDA at least 90 days before marketing the device.

Other general controls included adequate labeling and good manufacturing practices in producing devices. Drew (1986) reported 460 types of Class I medical devices, 27 percent of the total number of medical device types.

Class II devices, such as cardiac monitors, anesthesia machines and defibrillators, were subject to performance standards in addition to general controls. A performance standard was a set of specifications that the device must meet to be safe and effective.

The process of developing a performance standard was long and difficult: and no standards had been put in place by then. Approximately 1,100 types of devices, or 65 percent of the total, were included in Class II (Drew, 1986).

Class III devices were those with the greatest risk of injury, or that supported or sustained life and had an unknown degree of risk. They included artificial heart valves, heart-lung machines, and lithotriptor.

Class III devices were subject to general controls and premarket approval. This meant that firms must obtain FDA approval 
before marketing the device. Any devices thrt ware not marketed before the Medical Device Amendments were automatically Class III devices (unless FDA found that they were substantially equivalent to a Class I or Class II device). Approximately 140 devices were Class III, or 8 percent of the total (Drew, 1986).

Pre-market approval depended on the firm showing that the device is safe and effective, usually based on clinical studies or other clinical experience with the device. In order to develop clinical data for such approval, an investigational device exemption (IDE) had to be obtained from FDA. An IDE permitted limited distribution under specific conditions for the purpose of studying the device. The IDE provided for the clinical use of devices at a specific number of locations, based upon laboratory and animal tests which predicted that clinical use in humans would be potentially helpful to patients.

A number of regulatory requirements applied to medical device firms after marketing begins. The general controls (including registration, listing, and good manufacturing practices) continued to apply. The Food, Drug, and cosmetics Act required that FDA inspect all medical device manufacturers that produce class II or Class III devices at least once every two years. Companies who made only Class I devices were inspected at least once every four years. FDA could inspect a firm more frequently if problems occurred with its products. 
A more recent addition to the post-marketing requirements was the medical device reporting regulation, which went into effect in 1994. Under this regulation, medical device firms were required to report to FDA any death or serious injury that may be related to one of their products, as well as any malfunction that could have caused death or serious injury.

The Medical Device Amendments protected consumers in an area where the complexity of the technology prohibited them from personally assessing the safety and efficacy of the products used to prevent, diagnose or treat their illnesses. Although there was basic agreement within the medical device industry that FDA's charge of imposing social regulation was necessary, many manufacturers question the benefits versus the regulatory expenditures involved in compliance.

\section{Regulated Industry Research}

In 1985, Ungson, James \& Spicer evaluated the effects of regulatory agencies on organizations in the wood products and high techrologif flectronics inüustries. There were three distinct but related phases to their research. First, they conducted preliminary interviews with trade associations, regulatory agencies, and selected firms in the wood products and high technology/electronics industries to improve their understancing of business-government relationships. Second, they developed a survey questionnaire, and 
administered it to 80 firms in the two industries. They also obtained regulatory compliance costs of some firms and used these to corroborate questionnaire responses. Third, they conducted post hoc interviews with managers of 14 firms to clarify questionnaire findings and to elicit participants' reactions to the results.

Four specific hypotheses were stated and tested. Hypothesis 1 contended that sectors of the task environment varied in terms of importance, predictability, and controllability to organizations. They found that government regulatory agencies were significantly different from all other sectors in terms of predictability and controllability.

The second hypothesis contended that organizational adjustments to different sectors of the task environment varied. They found, for the most, part that adjustments made in both industries in response to regulatory agencies consisted in hiring and firing personnel and minor changes in work standards and procedures.

The third hypothesis contended that regulatory agencies differed in terms of how their positions were perceived by organizations, and that these differences hold among industries. They found the frequency of inspections and difficulty in obtaining regulatory information had consequences upon morale and were the most severe adverse characteristics of regulatory agencies. 
The fourth hypothesis contended that assessments of agency issues varied with the size and age of the firm. They found that larger, older firms granted greater importance to regulatory agencies in their planning activities. Younger, smaller firms perceived more harmful effects on morale arising from their interactions with regulatory agencies than did older and larger firms.

Within the medical device industry McRay (1986) attempted to investigate the effects of the 1976 federal regulation amendment within the diagnostic imaging industry. He questioned how the medical device regulation effected net entry (e.g., the difference between the number of firms entering and exiting and industry) and concentration (e.g., the distribution of sales among firms in the industry) .

Regressions coefficients were produced for both net entry and concentration spanning years 1970 to 1980 . He found that medical device regulation did not appear to significantly effect net entry or concentration in the diagnostic imaging equipment industry.

\section{Research Studies}

Parket \& Eilbirt (1975) attempted to measure the absoiute net income, profit margin return on equity, and earnings per share. Ninety-six firms responded to a survey. The profitability of 80 of these firms were compared to Fortune 500 firms. On all four 
measures, the 80 firms proved to be more profitable. Some of the limitations of the study included no adjustment for risk. There was a questionable sample; performance was measured over a short period of time (12 months); performance criteria were inadequate; no tests for significance were performed.

Heinz (1976) stipulated several measures such as return on assets, return on equity, and profit margins. He correlated Corporate Social Responsibility (CSR) ratings of 29 firms from a Business and Society Review survey with retirn on equity. A significantly positive correlation between corporate social responsibility and return on equity was found. However, the small sample size and reliance on a reputational rating system were limitations.

Sturdivant \& Ginter (1977) established performance criteria of earnings per share over a ten year period. A population of 67 high Corporate Social Responsibility (CSR) firms as identified by Moskowitz in the Business and Society Review were used in a survey. Twenty-three firms returned 130 questionnaires. The 67 firm population was also reduced to 28 firms and reclassified into four industrial groupings. Their research implied that high CSR firms (Best and Honorable Mention) outperformed low CSR firms. This study did not provide an adjustment for risk. They employed a $t$-test with a very small sample and the industrial categories were inconsistent. They also failed to identify a curvilinear 
relationship revealed in the data between corporate sccial responsibility and earnings per share.

Alexander and Buchholz (1978) measured stock price increases over two years and five years. They used reputation ratings derived from Business and Society Review surveys. Corporate Social Responsibility (CSR) ratings were correlated with stock price increases over time and adjusted for risk. They determined that CSR had no effect on stock market performance. This study seemed to be limited by reliance on a questicnable sampie and the performance measures were inadequate.

\section{Summary}

The role of government had been primarily to support business systems in their role of economic leadership and to mediate between business and society. Government's role had changed from judging how well business performed its social responsibilities to defining what these responsibilities should be. The role of government was enlarged to include a regulatory function. A wave of legislative regulation of business followed. The rapid expansion of government controls had been associated with a growing dissatisfaction with the effects of regulations.

Two widely accepted divisions of government regulation were economic and social. The basic reform strategy, according to Bardach and Ragan (1982), had animated the growth of federal 
protective regulatory programs and had created a series of regulatory agencies, all for the purpose of the betterment and improvement, both socially and economically, of the operation of business and industry.

The medical device industry had been subject to both social and economic regulation. Food and Drug Administration (FDA) was the designated regulating agency responsible for creating and issuing guidelines for the medical device industry. Several regulatory developments in the medical device industry culminated in the enactment of the Medical Device Amendments of 1976. The economic and social consequences of these amendments have beer evaluated since their enactment.

The research studies which had been reviewed were related to social regulation and profitability in several regulated industries. One study surveyed managers in the wood and high technology/electronics industry as to the social and economic consequences of federal social regulation. A second study looked at net entry and concentration in the diagnostic imaging equipment industry.

Further research studies were reviewed that employed survey questionnaires in evaluating organizational performance with respect to corporate social responsibility. 
Time To Equivalence

CHAPTER III

\section{METHODOLOGY}

\section{Introduction}

The study examined aspects of the impact of federal social regulation upon the time required to get a medical device through the FDA review process and onto the market for small and large firms in the orthopaedic medical device industry. The accomplishment of the study necessitated the collection of quantitative and opinion data from a geographically dispersed population of regulatory affairs managers. Data described the relationships and differences between elements of independent variables, company characteristics, managers' opinions, and the dependent variable, time to equivalence or FDA disposition.

The methods of research adopted were descriptive and comparative in nature. Accordingly, the design involved descriptive and comparative quantitative and qualitative data collected via a survey method.

The research questions were as follows:

1. What is the relationship between time devoted io establishing an FDA disposition of substantial equivalence for an orthopaedic medical device and related costs and resource consumption? 
2. Is there any difference between respondents (companies) who possess or do not possess certain identified characteristics and time required to establish equivalence?

3. Is there a any difference between time to equivalence and respondent's (company's) attitudes about selected characteristics of the regulatory process as having an impact on tirne to equivalence?

4. What combination of independent variable measures best predicts time to equivalence? This research question takes information from all the questions on the questionnaire.

5. What variables appear to have an impact on time to equivalence as perceived by the company respondent? This research question relates to questions number 4 and 10 on the questicnnaire.

\section{Choice of Method}

In the classical formulations of how best to apply social research to organizational behavior, one of the recommended earliest steps was to develop intelligence about the problem in question. This process included forming adequate conceptual and empirical definitions, and assembling or gathering sufficient empirical data to provide a description of the problem in terms of its size, organizational location, and spatial distribution of the problem in question. 
The prcsess described above has been attempted, to varying degrees of success, through the use of surveys investigating profitability and organizational behavior. Parket and Eilbert (1975) explored the profitability of 80 firms compared to Fortune 500. Their performance criteria were absolute net income and profit margin. Heinz (1976) correlated Corporate Social Responsibility with several measures such as return on equity and profit margins. He employed Business and Society Review survey ratings to compare 29 firms on profitability.

Sturdivant and Ginter (1977) had 23 firms return 130 questionnaires querying executives regarding profit growth over 10 year period. In addition, a classification procedure was employed to recategorize 67 sampled firms into four industrial groupings. Alexander and Buchholz (1978) used reputation ratings derived from Business and Society Review surveys. Social responsibility ratings were correlated with stock price increases over time and adjusted for risk. Aupperle, Carroll, \& Hatfield (1985) used a forceochoice survey instrument containing 20 items assessing strategic management and profitability. Eight hundred and eighteen chief executives listed in Forbes 1981 Annual Directory were sampled.

Ginsberg's dissertation work (1986) at the University of Pittsburgh measured environmental attributes, organizational size, and performance through the use of a questionnaire. Questions were designed to investigate the changing competitive environment of 
financial depc sitory institutions since the enactment of the Depository Institutions Deregulation and Monetary Control Act in 1980.

Resnick's dissertation (1986) focused on the airline industry just after government deregulation in 1978. He attempted to determine what corporate policies and practices resulted from externally imposed events requiring critical judgment and how those policies and practices affected employee education and training programs as reported by corporate training directors. The study selected the largest U.S. airlines, as identified by employee size in 1984 and listed in the 1984 U.S. Airline Handbook.

As evidenced by the use of questinnnairss cited above, a survey design which utilizes a questionnaire completed by top level executives is a viable and well recognized procedure for obiaining standardized information about organizational behavior and characteristics.

The survey design that was implemented in this study represented an attempt to achieve a satisfactory tradeoff between the goals of generalizability, contextual realism, and precision. Survey designs have three basic characteristics: (1) systematic measurements were made over a series of cases yielding a rectangle of data; (2) the variables in the matrix were analyzed to see if they show any patterns; and (3) the subject matter was social (Marsh, 1982). 
Babbie (1973) identified three basic types of survey designs: (1) cross-sectional surveys; (2) longitudinal surveys; and (3) cross-sectional surveys that approximate longitudinal ones.

In a cross-sectional survey, data were collected at one point in time from a sample selected to describe some larger population at that time. In a longitudinal survey, data were collected at different points in time and the research was able to report changes in descriptions and explanations.

Major examples of longitudinal designs were trend, cohort or panel studies. Trend studies collected data from the same general population at different times. Cohort studies collected data from the same specific population at different times. Danel studies collected data from the same specific sample at different times.

In an "approximately longitudinal" survey, the data were collected at one point in time. Questions were presented which involved some notion of actual and perceived changes at different points in time. Examples of these questions were changes in employee size at progressive one year intervals from 1976 to present and perceived influence of regulatory documents produced by the federal government which stipulated guidelines at progressive one year intervals.

Some scholrurs might argue that research on organizational change can only be considered genuinely longitudinal when data are collected at different periods of time. Miller \& Friesen (1982) 
defined longitudinal research as "those techniques, methodologies and activities which permitted the observation, description, and/or classification of organizational phenomena in such a way that process (i.e., any sequence of changes in organizational variables) can be identified and empirically documented".

Given the difficulties involved with collecting nanel data (e.g. expensive, require a long time to collect, and face problem of sample attrition), a broader definition of "approximately longitudinal" was employed in order to support the utilization of "approximately longitudinal" designs that used retrospective data collection in investigating profitability and regulations.

Gregson (1975) and others found that descriptions of historical events become increasingly unreliable over time. This was due to loss of memory and the recency effect (i.e., the tendency to rationalize and distort accounts of past behavior in terms of subsequent and more recent events and conditions).

Nevertheless, there were also studies which showed that there was no significant difference in accuracy between recalling behavior which occurred 10 or more years ago and behavior which occurred two or three months ago (Gutek, 1978). It had also been shown that retrospective reca.l of past earnings was not substantially less accurate than that obtained for current salary (Ferber \& Birnbaum, 1979). 
Moreover, Powers, Goudy, \& Reith (1978) conducted a study which indicated that while recall techniques may have little utility for descriptive purposes, they may be used cautiously in correlational studies. Finally, there was evidence which showed that survey methods employing collection of retrospective or recall data were reliable provided certain precautions (such as not asking respondents to describe events that have a strong emotional component regarding themselves) were taken (Moss \& Goldstein, 1979 ; Power \& Huber, 1982).

\section{Research Population}

Although medical equipment companies in this country have had a fairly stable and rapidly growing economic and technological environment, orthopaedic medical device manufacturers have been directly tuuched by regulatory change due to the risk they pose. Other reasons for focusing on companies that manufacture orthopaedic medical devices include the following: (1) they represent a relatively homogeneous group; (2) they represent approximately 10-15\% of the 40,000 - 50,000 medical devices that cover the 1700 types sold in the U.S. and will be used at least once by each man, woman and child in this country and many others; (3) accessibility to regulatory affairs managers is relatively high. 
Time To Equivalence

Data sources were small and large orthopaedic medical device manufacturing firms throughout the United States. Selection of firms began with a review of The $510(k)$ Register in which was listed all companies that have filed $510(k)$ premarket notifications since the enactment of the 1976 medical device amendment. The $510(\mathrm{k})$ Reqister provided a product index which distinguished 19 different medical device classifications of which orthopaedic was one. Within each classification was a product coding system. Firms were chosen froin product coding categories which had no less than ten firms represented. There were two reasons for this selection process: (1) these categories represented companies that were diverse in terms of size and number of products manufactured, and (2) these companies functioned in the most competitive markets.

\section{Instrumentation}

A researcher-designed survey questionnaire was constructed to enable specific categorization of data. The most appropriate technique of observation for collection of data from firms' management was through use of a questionnaire. But a review of the literature showed no standardized instrument had been developed to measure the research dimensions of the relationships and comparisons among the particular variables of the present research.

The final instrument consisted of a letter of transmittal (Appendix B) and a questionnaire (Appendix C) with instructions. 
The questionnaire was designed to capture quantitative data and to quantify opinion data. The questionnaire consisted of tinree pages. The first two pages contained tables which provided the subject with a quantitative framework through which relationships and comparisons could be made from 1977 through 1987. The third page contained a table which provided the subject with a gualitative framework through which comparisons among elements of variables could be indicated quantitatively.

The design of the questionnaire was guided by two primary objectives: 1) assure the capture of complete data, and 2) facilitate the ease and speed of completion. As a result, the first two pages of the survey consisted of binary responses or short, numeric fill-ins. This constituted a combined closed and open form question design.

Since the principal objective of this study was to evaluate the influences on timely compliance over time (1977 - 1987), questions one through four were ordered chronologically. This allowed for historical comparisons and associations with events in industry and government. In addition, initial, pre-study interviews with regulatory affairs managers in which open-ended questions were asked indicated that continuity and clarity would be preserved if the questionnaire was designed as presented in Appendix $c$.

Questions five through ten were also designed to evaluate the influences on timely compliance. Questions five through nine were 
constructed as Iikert attitude scales. Favorable or unfavorable attitudes on five Likert-type categories were requested. Although the respondents were familiar with the subject matter, a "no opinion" category was supplied as one alternative to assure that each question was completed. Question ten was included as an openended query designed to yield information which may not have been addressed on the questionnaire. Although the pilot study which was incorporated into this research had as one objective the prioritization of questions, it was felt that the respondents needed one other vehicle to express their perceived influences on timely compliance.

The letter of transmittal was designed as suggested by Borg and Gall (1979). Those intentions which guided the design of the transmittal letter were as follows: 1) give the respondent a good reason for completing the questionnaire, 2) explain the purpose of the study, 3) reference the respondent's professional status, 4) emphasize the importance and significance of the study, 5) assure the respondent's anonymity, and 6) offer to send the respondent a copy of the results.

In addition, the transmittal letter was refined through the pilot study. The participants were asked to evaluate the transmittal letter with regard to composition, realism, accuracy, and relevancy. Appendix A includes the pilot study cover letter. 
Time To Equivalence

\section{Pilot study}

A pilot study was incorporated due to the lack of research documented in the literature which provided information relevant to this research. Minimal information was available about the medical device industry, regulatory professionals, the regulation of medical devices, and the interaction of all three.

In an effort to standardize and validate the content, format, and delivery of the research questionnaire, a sample of 14 representative medical device manufacturers were asked to participate in the pilot siudy. This selection process, although not subjected to any form of randomization, was purposive. The pilot study participants were chosen based upon their knowledge of the industry, their willingness to participate, and their interest in the research project.

Six participants or questionnaire evaluators were queried via the mail. A cover letter soliciting their assistance in the pilot study (Appendix A), the transmittal letter (Äppendix B), and the questionnaire (Appendix C) were forwarded. Their comments were requested regarding both the transmittal letter and questionnaire.

Eight participants or reviewers were interviewed by this researcher at the 1989 Annual Regulatory Professional Society meeting in Washington, D.C. Comments were sought regarding the content and validity of the questionnaire. Specifically, these reviewers were asked to consider each questionnaire item's 
relevance to the purpose of the study, that is, timely compliance. The logic and soundress of each item was assessed. Then the questionnaire was reassessed as a composite entity. This form of evaluation primarily consisted of face validity comparisons rather than content validity. In addition, since no criterion measures were available with which to correlate the questionnaire items, predictive and concurrent validity checks were not possible.

Do to the nature of the test or questionnaire, it was difficult to calculate a coefficient of internal consistency or equivalence. As a result, the unavailability of an alternative form of the questionnaire mandated the calculation of a coefficient of stability only. Furthermore, this test-retest reliability measurement was limited to four respondents. The delay in administration was one day, approxidately 24 hours. The reliabiliti coefficient was computed to be 898 .

However, this meeting in Washington permitted pre-study establishment of baseline variable values. All of these respondents were regulatory affairs professionals actively employed within the medical device industry.

All suggestions and comments were collected. Suggestions were incorporated if conseñsus (more than one reviewer had a similar concern) was reached regarding a variable. One consequence of this review process was the elimination of two questions which focused on the direct impact of compliance upon time to equivalence as it 
relates to increased or decreased production costs. Most reviewers feit unqualified to supply specific information regarding production costs since this was not their area of expertise. overall, the reviewers found the transmittal letter and questionnaire did address the research questions being evaluated in this research endeavor.

\section{Procedures}

\section{Questionnaire Mailing}

The survey design for this study entailed a transmittal letter and grestionnaire mailed to orthopaedic medical device manufactures. The Director of Regulatory Affairs or the person responsible for filing section $510(\mathrm{k}) \mathrm{s}$ for the company was asked to complete the questionnaire and return it in a self-addressed, stamped envelope.

The sample consisting of 27 different orthopaedic device categories was drawn from a population of over 245 orthopaedic device categories. These 27 device categories represented 5 Class I devices, 21 Class II devices and 1 Class III device. Figure 1 below details the orthopaedic device classification category supplied in The $510(\mathrm{k})$ Register and the FDA device classification provided in the Federal Register (1987). 


\section{Figure 1}

\section{Orthopaedic Device Classification Category}

and

FDA Device Classification

\begin{tabular}{|c|c|}
\hline Device Category & ation \\
\hline Operating Room Accessories & II \\
\hline Bone Fixation Plate & II \\
\hline Arthroscope & II \\
\hline Pemorotibial, Semt-constrained Knee Prosthesis & II \\
\hline Intrameduliary Pixation Rod & II \\
\hline Mon-powared Itxatton Apparatiss & II \\
\hline Bemorotibial, Non-constrained Kaee Prosthesis & II \\
\hline Pnemmatic Powered Surgical Instrumeat & II \\
\hline Porceps & $\mathbf{I}$ \\
\hline Smooth Fixation P1n & II \\
\hline Orthopaedic Cutting Instrument (Saw) & II \\
\hline Bone Pixation Scren & $I I$ \\
\hline AC Powerad Motor Surgical Instrument & II \\
\hline IImb Brace Orthosts & $I$ \\
\hline Cast, Bandage & $I$ \\
\hline Semt-conatrafned Blbow Prosthesis & II \\
\hline Semt-constrained H1p Metal/Poly Prosthesis & II \\
\hline Semi-constrained BIp Metal/Acetabular Prosthesis & II \\
\hline Invasive Traction Component & II \\
\hline $\begin{array}{l}\text { Semi-constrained Knea Patello/femorotibial Prosthests } \\
\text { DC Powered Surglcal Instrument }\end{array}$ & II \\
\hline Comblned Mafl/Blade/plate Flxation Appliance & II \\
\hline Bent-Iemoral BIp Matal Prosthesis & $I I$ \\
\hline Interlaminar Spinal Pixation Appliance & $\mathbf{I}$ \\
\hline Son-constralned, Cemented Shoulder Prosthesis & III \\
\hline Zemt-femoral B1p Motal/Polywar Prosthesis & II \\
\hline Cast Component & $\mathbf{I}$ \\
\hline
\end{tabular}


Time To Equivalence

The listing above constituted 553 devices manufactured by 148 different companies from 1976 to 1987. This sample was drawn from over 950 orthopaedic devices manufactured by over 670 orthopaedic medical device manufacturers. The rationale for this sample selection was based on a selection criteria that the device category have a minimum of ten companies manufacturing devices between 1976 and 1988. The $510(R)$ Register lists all submissions by device category since 1976. A cursory review of this document would reproduce with minimal computation this same list of evaluated categories.

One hundred and six of the 148 device manufacturers were sent questionnaires. Contact with 42 manufacturers was not established due to relocation, non-existence, or insufficient information. Completed questionnaires were returned to the University of San Diego.

\section{Data Collection and Follow-up}

Within approximately two months, 28 questionnaires were returned for a return rate of 268 . Useful information was available on 24 of those 28 returned forms. Among those four returned forms with unusable information, the most common reason given for lack of response was the respondent's feeling that he or she could not supply appropriate information. Since the return of 24 forms represented only 128 device submissions between 1976 and 1987 for 
Time To Equivalence

a follow-up rate of $23 \%$, further information was sought through phone interviews.

The phone interview process was structured so that only one independent interviewer was utilized. A phone contact scenario was constructed which facilitated the gathering of information similar to that obtained on the mailed questionnaire. Phone interviews took 4 - 5 minutes to complete. Approximately 8 - 10 hours were devoted to the phone interview process. Less than 58 of those contacted refused to participate in the study. Most participants were on the East Coast and unavailable for interview because of conflicting time frames, other obligations, or vacations.

An additional 15 manifacturers were contacted via the phone. This sample was drawn from the remaining 78 manufacturers who did not return the original mailing. The remaining 78 companies were prioratized based upon the number of submissions they had made between 1976 and 1987. This process was randomized in that not all subjects were contacted directly upon the first phone call. If a responcient was not reached upon the first call, he or she was not called again until the last subject on the list had been called. The list was then initiated again from the beginning.

The questionnaire mailing and the phone interviews combined to produce 39 completed questionnaires with a return rate of 378 . This also increased the device submission number to 263 for a return rate of 47.58 .

Page 51 
Time To Equivalence

\section{The Research Approaches and Data Analysis}

\section{Approach I}

The first level of analysis dealt with Research Question Number 1. The research approach was a descriptive-correlational survey. Its purpose was to determine the relationship between three characteristics of the orthopaedic medical device manufacturing company and time to equivalence. Fox (1969) stated that a correlational survey was "a survey designed to estimate the extent to which different variables are related to each other in the population of interest".

Least square regression coefficients were developed based upon the straight-line relation between two variables summarized in the following equation:

$$
Y=B_{0}+B_{1 x}+\varepsilon \text {. }
$$

In an effort to better represent how the dependent variable related to the independent variables, a curvilinear model was also developed. Polynomial equations and quadratic models were represented by:

$$
y=b_{0}+b_{1} z+b_{2} x^{2}
$$

These analyses were stratified by year, if data permitted.

The Appendix D summarizes the hypotheses related to Research Question Number I. 
Time To Equivalence

\section{Approach II}

The second phase of the analysis addressed Research Questions 2 and 3. This analysis compared 2 to 5 levels of 10 independent variables with one independent variable, time to equiralence. Since all comparisons involved two or more groups, one-way analysis of variance (ANOVA) was utilized to detect differences between groups or independent variable levels.

ANOVA involved deciding if the variation due to differences between groups was largex than would be expected by chance. If the error variaiion represented the natural variation that would be expected with chance, and if the variation between groups was large relative to the error variation, the group means were likejy to be different.

However, the assumptions underlying the F-distribution of the ANOVA were not met in most comparisons. When the assuriptions underlying ANOVA were tested, it was determined that data imbalances and group variances existed for most groups. As a result, the ANOVA analogue, the Kruskal-Wallis test was used. Rruskal-Wallis chi-square approximations were tested for each analysis of variance.

These analyses were stratified by year, if data permitted.

Appendix E summarizes the hypot,neses related to Research Questions 2 and 3 . 
Time To Equivalence

\section{Approach III}

This applied to Research Question Numbers 4. This third level of analysis was the statistical task of calculating regression coefficients and heta weights. Since the regression coefficients could not be compared against one another in an attempt to determine which of the various predictor variables was the best predictor variable, converted beta weights were computed. Beta weights were determined for each predictor variahle. The predictor variable that had the largest beta weight, disregarding whether the beta weight was positive or negative, was the best predictor.

Significance levels were established at 0.05 when evaluating if a particular bet.a weight was different from zero. If a particular predictor variable was not helping very much to decrease the difference between the predicted and actual criterion scores, then the beta weight for this predictor variable will be close to zero.

This analysis was restricted to information representing the most recent company status. Therefore, comparisons were made for 1987 only.

Appendix F summarizes the hypotheses related to Research Questions 4 .

\section{Approach IV}

This fourth ievel of analysis was primarily descriptive. It addressed information supplied through questions 4 and 10 on the 
Time To Equivalence

questionnaire. These questions requested the respondent supply opinion information. This yielded data which was qualitative in nature and nominal on type.

Frequency tables were generated. Tendencies were evaluated through imposed stratifications relating to the following conditions: number of years manufacturing medical devices, number of employees in the organization, number of devices manufactured, presence of an in-house regulatory department, use of outside regulatory consultants, and regulatory training experiences.

All statistical analysis, runs, tables and graphs are produced through PC based SAS statistical package. The SAS procedures which were employed were FREQ, REG, ANOVA, and NPARIWAY.

\section{Criteria for Data Sources}

Several criteria were used to select data sources and include the following:

Criteria 1. Documents have to be related to orthopaedic medical device firms in the United States.

Criteria 2. Selected device categories have no less than ten devices manufactured between 1976 and 1988 .

Criteria 3 . Selected firms have a regulatory affairs department and manager or some person responsible for regulatory arfairs.

Criteria 4. The person within each firm to whom the request for data was addressed was the regulatory affairs manager or person responsible for filing $510(\mathrm{k}) \mathrm{s}$. 


\section{Summary}

The chapter presented the methodology by which the research design was produced. The study examined the relationship among three independent variables and one dependent variable, time to equivalence. The study further compared differences between twelve independent variables and one depencert variable, time to equivalence. Data were collected from a population of small and large orthopaedic medical device manufacturing companies dispersed throughout the United States.

To accomplish the study, a mailed, researcher-designed questionnaire was used. Phone interviews were also employed to facilitate follow-up and clarify subject responses. Validity and reliabiiity of the instrument were discussed based upon a pilot study conducted to determine necessary changes in the instrument.

The procedure of the experiment was specified in this chapter and the steps which achieved selection of firms for the study were outlined. Delineation of the data collection process and folloryup rates was provided.

This chapter concluded with designation of the four research approaches and data criteria which guided the statistical analyses in this study. 
CHAPTER IV

DATA ANALYSIS

The chapter presented an analysis of data relative to the relationship of three elements of the independent variables, organizational costs and resource consumptions, and one dependent variable, time to equivalence (days). These relationships were evaluated over time. Further analysis included the measurement of mean differences in time to equivalence for five elements of the independent variable, organizational characteristics. Additional analysis was performed relative to the mean scores of the dependent variable, time to equivalence, and the five independent variables, five classes of attitudes toward perceived influences on time to equivalence. The relationship relative to all twelve elements of the independent variâle, organizational characteristics, and the dependent variable, time to equivalence, were also analyzed. The last analysis with regard to the respondent's perceived influences on timely compliance was descriptive in nature.

These analyses were made for the five research questions. For the first question regarding the relationship of time to equivalence and crganizational costs and consumptions a regression line was fit to describe the relationship. For the second question regarding differences in time to equivalence relative to specified company characteristics, comparative analysis was performed over 
Time To Equivalence

time. The trird question germane to time to equivalence and five classes of attitudes also involved comparative analysis. The fourth question required regression coefficients be converted into beta weights to best predict time to equivalence. The five question entailed frequency distributions of perceived influences on time to equivalence.

\section{Unit of Analysis}

Although survey research provided techniques for examining practically any unit of analysis, typically such units were persons. Nevertheless, numerous surfeys have been conducted in order to gather information from iruaviduals or "informants" about organization-level variables such as strategy or profit influences.

Venkatraman and Grant (1986) have identified two approaches that have been commonly adopted for operationalizing organizationlevel constructs. One approach was the collection of data from a designated executive with an implicit assumption that the responses reflect organizational characteristics of interest. The second approach suggested the collection of data from multiple respondents from which the mean was calculated to represent an organizational score.

This study utilized the first approach suggested above. The Director of Regulatory Affairs or the executive responsible for filing section $510(k) s$ was the designated subject who supplied responses. 
Time To Equivalence

\section{Medical Device Categories}

The questionnaire and phone interview processes resulted in the return distribution illustrated in Figure 2 below. The device categories were listed in the sequence provided through the $\underline{510(\mathbf{k})}$ Register. The second column in Figure 2 headed by Comp. represented the number of companies with device submissions to FDA in each device category. The third column headed Sub.listed the number of device submissions among the indicated companies and within a specified device category. 


\section{Figure 2}

Orthopaedic Medical Device Categories, Number of Companies, and

Number of Device Submissions per Category

\begin{tabular}{|c|c|c|c|}
\hline & Device Categary & comp. & $\mathbf{s u b}$. \\
\hline 1 & Operating poom Accessories & 1 & 1 \\
\hline 2 & Bone Fixation Plate & 4 & 6 \\
\hline 3 & Arthroscope & 13 & 26 \\
\hline 4 & Pemorotiblal, semi-con. Inee Prosthesis & 7 & 22 \\
\hline 5 & Intramodallary Plxation Rod & 5 & 8 \\
\hline 6 & Man-powared Fixation Apparatus & 6 & 11 \\
\hline 7 & Penorotiblal, Mon-con. Inee Prosthesis & 8 & 20 \\
\hline 8 & Premmatlc Poured surglcal Instrument & 4 & 4 \\
\hline 9 & Porcepss & 2 & 2 \\
\hline 10 & Bwoth Pixation P1n & 2 & 2 \\
\hline 11 & Orthopaed1c Cutting Instrament (Saw) & 2 & 2 \\
\hline 12 & Bone PIxation Screw & 6 & 7 \\
\hline 23 & AC Powered Motor Surgical Instrument & 3 & 3 \\
\hline 14 & Ifmb Brace Orthosis & 1 & 1 \\
\hline 15 & Cast, Bandage & 2 & 2 \\
\hline 16 & Semi-constrained Elbow Prosthesis & 2 & 4 \\
\hline 17 & 8enf-con. B1p Matal/Poly Prosthesis & 19 & 58 \\
\hline 18 & Eem1-con. B1p Motal/Acetabular Pros. & 8 & 11 \\
\hline 19 & Invasive Traction componont & 4 & 8 \\
\hline 20 & Seml-cons. Knee Patello/Pemorotiblal Pros. & 11 & 27 \\
\hline 21 & DC Ponared Surgical Instrumont & 2 & 2 \\
\hline 22 & Coablned IasI/Blade/Plate PLxation Appl. & 4 & 9 \\
\hline 23 & Eemi-feworal Efp Metal Prosthesin & 9 & 15 \\
\hline 24 & Interlaminar Splnal F1xation Appliance & 3 & 4 \\
\hline 25 & Don-constrafned, Cemented Bhoulder Pros. & 5 & 9 \\
\hline 26 & Beent-femoral Blp Meral/Polymar Pros. & 7 & 8 \\
\hline \multirow[t]{2}{*}{27} & Cast component & 1 & 1 \\
\hline & Iotal & 263 & \\
\hline
\end{tabular}


Time To Equivalence

The above listing supplied information about the sample of companies in this study who made submissions from 1977 through 1987. This represented a homogeneous sample of orthopaedic medical device categories. The purposive selection process provided for a fairly homogeneous sampling. In addition, selection bias did not seem tc influence the device distribution.

The following sestion described the results of this investigation. All hypotheses were stated in the null.

\section{Results of Analysis \\ Research Questions}

Research Question Number 1.

What is the relationship between time devoted to establishing an FDA disposition of substantial equivalence for an orthopaedic medical device and related costs and resource consumption?

Hypothesis 1.1. There is no relationship between time (days) needed to establish equivalence and the number of years a company has been manufacturing medical devices.

The equation for the fitted straight iine was:

$$
\text { DAYS }=b_{0}+b_{1} \text { YEARS }
$$


Time to Equivalence

Tabie 1 represents the results of the least square regression relating days to the number of years manufacturing medical devices. The principle of least squares involved fitting a line through the points (i.e., days to equivalence) so that the vertical differences between all the points and the line were minimized. The "best" line was the line that minimized the sum of squared differences, hence the name least squares.

Table 1

Model Relating Variable DAYS TO EQUIVALENCE to

Variable YEARS MANUTACTIURING

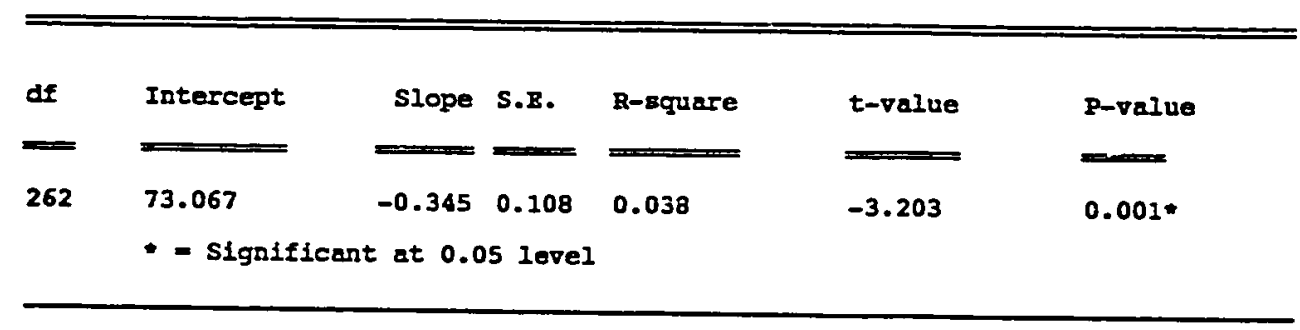

The equation for the fitted straight line with the values from Table 1 inserted was now:

Times to Equivalence(Dags) $=73.067+(-0.345)$ Years Hanufacturing

By completing this equation, it was apparent that 73.067 days was the predicted mean time to equivalence if zero was sibstituted for the number of yeare manufacturing nedical devices. This was the value of time to equivalence (days) at the point where the fitted 
Time to Equivalence

line intercepted the vertical axis. Under these circumstances, the intercept gave an estimate of the average number of days required to establish equivalence when a company had no manufacturing experience. The slope of the line was the amount of decrease in predicted days to equivalence that would result from an increase in one year of manufacturing experience.

As a result, the predicted mean number of days to equivalence for a company manufacturing medical devices one year would be 72.722 days. The predicted value for a company with five years of manufacturing experience would be 71.338 days. The predicted value for ten years experience would be 69.608 days. The predicted value of 42.277 days resulted when considering the oldest company in this study with 89 years manufacturing experience.

The R-square value of 0.0378 indicated that little, if any, of the variation in the data was accounted for in the proposed model. This value also reflected a low level magnitude with regard to the relationship of days to equivalence and number of years manufacturing. The low level R-square value indicated that other variables may have been needed in the equation to account for variation in the data. However, this finding does not contradict the significance of the relationship which was found to exist between the number of years manufacturing and days to equivalence. The analysis related to Research Question Number 4 below further illustrated the impact of other variables in the regression equation. 
Time to Equivalence

However, upper and lower 958 prediction limits were calculated to further elaborate on the magnitude of this relationship. These calculations allowed for bounds to be put around a single predicted value. These bounds gave a probable range for the number of days to equivalence that were required given the number of years manufacturing. The magnitude of the relationsisip was further enhanced through these computations since the prediction limits took into account the variation in the dependent variable for observations with the same value of the independent variable. These limits also took into account any error in the fitted regression Iine.

For example, a company with four years experience in manufacturing devices had an average predicted time to equivalence equal to 71.68 days. The 958 limits were -27.88 and 171.2 days. This meant that there was a 958 confidence level that the number of days to equivalence for a company with four years manufacturing experience was somewhere between -27.88 and 171.2 days. This wide of a range was a result of variation in days to equivalence values caused by factors other than the number of years manufacturing.

Realizing the possible need for another term or factor in the regression model which would better represent the relationship between days to equivalence and number of years manufacturing, a quadratic regression equation was introduced to fit the rurve. Table 2 below supplies the results of those computations. 
Time to Equivalence

Table 2

Quaciratic Model Relating Variable DAYS TO EQUIVALENCE to Variable YaARS MANUFACTURING

\begin{tabular}{|c|c|c|c|c|c|c|}
\hline$d f$ & Intercept & Slope & S.R. & R-equare & t-value & P-value \\
\hline 262 & 83.026 & 0.008 & 0.005 & 0.0473 & 2.609 & 0.109 \\
\hline
\end{tabular}

The quadratic model produced a $t$-value for years (squared) equal to 1.609 and statistically significant at the 0.1088 level. This indicated that there was 1 chance in 10 of getting a $t$ statistic as large as the one for years squared. This seemed to suggest there was no need for imposing the quadratic model to better represent the relationship between days to equivalence and number of years manufacturing.

Although a low-level correlation seemed to exist between days to equivalence and number of years manufacturing, Table 1 did provide other selevant information. The $t$-value of -3.203 with the probability of 0.0015 rejected the null hypothesis that the slope equaled zero. The p-value for the $t$-value of 0.0015 supplied evidence that tins slope was not zero. In other words, increasing the number of years manufacturing medical devices did produce a statistically significant decrease in the number of days required to reach equivalence.

In conclusion, the null hypothesis was refected in favor of the alternative that a relationship did exist between the number 
Time to Equivalence of years manufacturing orthopaedic medical devices and the number of days required to establish equivalence. Albeit the correlation between number of years and days was equal to 0.194 and only 48 of the differences among the companies who manufactured medical devices in terms of years was predictable on the basis of differences in the days to equivalence, increasing the number of years a company manufactures medical devices did produce a statistically measurable decrease in the number of days required to establish that a medical device was equivalent to another device manufactured prior to 1976 .

Hypothesis 1.2. There is no relationship between time (days) needed to establish equivalence and the number of employees in an organization.

Table 3 represents the results of the least square regression relating days to the number of employees in the organization. This analysis was applied to the years 1977 through 1987. 
Time to Equivalence

Table 3

Model Relating Variable DAYS TO EQUIVALENCE to Variable NUMBER OF EMPLOYEES IN ORGANIZATION

\begin{tabular}{lllllll} 
Year & df & Intercept & Slope & S.E. & t-value & P-7alue \\
\hline 1977 & 137 & 58.697 & -0.003 & 0.010 & -0.256 & 0.7981 \\
1978 & 194 & 53.713 & 0.015 & 0.007 & 2.295 & 0.0228 \\
1979 & 194 & 54.083 & 0.015 & 0.007 & 2.330 & $0.0209 *$ \\
1980 & 217 & 58.026 & 0.014 & 0.007 & 2.183 & $0.0301 *$ \\
1981 & 217 & 58.997 & 0.014 & 0.006 & 2.100 & $0.0369 *$ \\
1982 & 220 & 60.653 & 0.015 & 0.006 & 2.271 & 0.0241 \\
1983 & 220 & 56.843 & 0.011 & 0.006 & 1.709 & 0.0888 \\
1984 & 227 & 60.652 & 0.010 & 0.007 & 1.332 & 0.1843 \\
1985 & 234 & 65.463 & 0.007 & 0.007 & 0.935 & 0.3509 \\
1986 & 240 & 63.196 & 0.006 & 0.007 & 0.856 & 0.3928 \\
1987 & 243 & 64.709 & 0.005 & 0.007 & 0.713 & 0.4763
\end{tabular}

- - Significant at 0.05 level.

The data listed in Table 3 seemed to indicate that there existed a positive relationship between the number of employees in an organization and the number of days needed to establish equivalence. The only exception to this premise was in 1977 where there seemed to be a negative relationship.

One possible reason for the existence of a negative relationship in 1977 was the fact that the 1976 amendment positioned both FDA and industry in an arena that was new for both. FDA was uneducated and did not require all regulatior.s be met; thus, establishing equivalence in a shorter period of time. Industry, realizing a need to satisfy new federal regulations, 
Time to Equivalence

employed more personnel to meet these new regulatory demands. Consequently, as the number of employees rose, time to equivalence declined.

Albeit, the years from 1978 to 1982 seemed to provide evidence at the 0.05 significance level that the pattern observed in 1977 was being reversed: as the number of employees in a company increased so did the number of days needed to establish equivalence. Clarity regarding this trend was furnished again by the status of the agency and industry in unison. As the agency matured in its regulatory responsibilities, so did the requirements for compliance. This naturally increased the days to equivalence. The medical device industry, as mentioned above, continued to bring in more employees to meet the regulatory requirements. This increase in employees was seen in many departments other than the regulatory department. Those departments with new demands as a result of the 1976 amendment were: manufacturing, quality assurance, Research and Development, advertizing, sales, and marketing.

Statistically significant relationships declined or were nonexistent from 1982 th 1987 . In fact, the relationship seemed to progressively decline as each year passed. The rationale for this Isvielation resied primariiy witn industry at this juncture. FDA continued to make regulatory requests for compliance and, as a result. time to equivalence increased. However, industry departments became saturated and discovered that continued employee 
Time to Eqüivalence

recruitment was not reducing time to equivalence.

Consequently, the null hypothesis was rejected from 1978 through 1982. A positive relationship existed between time to equivalence and the number of employees in an organization. From 1978 to 1982, organizational employee size increased as did time to equivalence. The null hypothesis was retained from 1982 to 1987. The number of employees in the organization did not have a statistically significant impact time to equivalence.

Hypothesis 1.3. There is no relationship between time (days) needed to establish equivalence and the number of employees in the regulatory department.

Table 4 represents the results of the least square regression relating days to the number of employees in the regulatory department. This anaiysis was applied to the years 1977 through 1987.

Page 69 
Time to Equivalence

Table 4

Model Relating Variable DAYS TO EQUIVALENCE to Variable NUMBER OP EMPLOYEES IN THE REGULATORY DEPARTMENT

\begin{tabular}{lllllll} 
Year & df & Intercept & slope & S.B. & t-Value & P-value \\
\hline 1977 & 137 & 58.446 & -0.451 & 1.042 & -0.433 & 0.6658 \\
1978 & 194 & 56.471 & -0.245 & 1.088 & -0.225 & 0.8223 \\
1979 & 194 & 56.888 & -0.423 & 1.145 & -0.369 & 0.7124 \\
1980 & 217 & 60.218 & -0.926 & 1.035 & -0.894 & 0.3721 \\
1981 & 217 & 61.092 & -1.092 & 1.049 & -1.041 & 0.2991 \\
1982 & 220 & 62.277 & -1.275 & 0.977 & -1.305 & 0.1933 \\
1983 & 220 & 59.974 & -0.885 & 0.982 & -0.901 & 0.3685 \\
1984 & 227 & 63.794 & -1.305 & 1.020 & -1.279 & 0.2021 \\
1985 & 234 & 67.870 & -1.813 & 1.014 & -1.789 & 0.0749 \\
1986 & 240 & 65.444 & -1.495 & 0.986 & -1.515 & 0.1310 \\
1987 & 243 & 66.804 & -1.576 & 0.938 & -1.680 & 0.0942 \\
\hline
\end{tabular}

Review of Table 4 indicated that the number of days required to reach equivalence seemed to increase with time. There was no consistent evidence that there existed a relationship between the number of employees in a regulatory department and the number of days necessary to get a medical device through the regulatory review prccess.

Years 1985 and 1987 were the only years in which increasing the number of employees in a regulatory department seemed to significantly, although not statistically significant, decrease at the 10 level the number of days to equivalence. Although not statistically significant, the number of employees in a regulatory department did seem to negatively impact the number of days to 
Time to Equivalence equivalence at every time interval. In other words, it seemed apparent that an increase in the number of employees in the regulatory department resulted in fewer days required to establish equivalence. As time went on, regulatory employees increased and time to equivalence (days) decreased. This would seem to suggest that the time required to get a device through the FDA review process may be decreased by increasing the number of employees in the regulatory department.

\section{Research Question Number 2}

Is there any difference between respondents (companies) who possess or do not possess certain identified characteristics and time required to establish equivalence?

Hypothesis 2.1. There is no difference between the type of medical device manufactured and time to equivalence.

Since the assumptions of normality and homogeneity of the parametric F-test were not met for this hypothesis, the RruskalWallis test was utilized in an effort to make the study findings more generalizable. The kruskal-Wallis test assumes that the variables under study have an underlying continuous distribution and are measured on at least an ordinal level. The results of that analysis is provided in Table 5 . 
Time to Equivalence

Table 5

Wilcoxon Scoras (Rank Sums) for Variable DAYS

TO EQUIVALENCE Classified by Variable TYPE OF DEVICE

Class N Expected Std Dev Mean Score

\begin{tabular}{llllc}
\hline \hline & & & & \\
Class I & 245 & 32340.0 & 265.12 & 131.38 \\
Class II & 15 & 1980.0 & 243.50 & 151.43 \\
Class III 3 & 396.0 & 111.50 & 85.00 \\
RruskaI-Wallis & Test & (Chi-Square Approximation) \\
CHISQ $=2.9543$ & df $=2$ & Prob > CHISQ $=0.228$ \\
\hline
\end{tabular}

The null hypothesis was retained. The calculated chi-square value did not exceed the critical value at the predetermined level of significance $(0.05)$. There did not appear to be a difference between the type of medical devices manufactured and the number of days needed to establish equivalence.

Inspection of the data seemed to indicate that Class I devices had a lower mean days to equivalence than class II devices; however, not statistically significant. Since there were only three Class III submissions within our sample, the mean value was suspect. However, this pattern was not aberrant since the proportion of submissions within the total population was approximately distributed as represented in Table 5 .

The chi-square value of 2.95 with prob $>0.228$ was less than the reference probability value of 0.25 . Therefore, there was a 258

Page 72 
Time to Equivalence

chance that whatever difference that existed between the types of medical devices as they related to days to equivalence was not due to random error. Thus, whatever differences that seemed apparent did not signify genuine population differences.

The nonparametric analogue, Rruskal-Wallis tests were performed sor the following hypotheses related to Research Question Number 2. Tables 6 through 9 detail the results of that analyses. All comparisons were stratified by years 1977 through 1987.

Hypothesis 2.2. There is no difference between companies having in-house regulatory departments and companies that don't have in-house regulatory departments on time to equivalence.

Page 73 
Table 6

Wilcoxon Scores (Rank Sums) for Variable DAYS

TO EQUIVALENCE Classified by Variable REGULATORY DEPARTMENT

\begin{tabular}{|c|c|c|c|c|c|c|}
\hline Year & Clase & $\mathbf{B}$ & Meen & df & CHISQ & Problatiso \\
\hline \multirow[t]{2}{*}{1977} & Yes & 203 & 127.49 & 1 & 3.12 & 0.077 \\
\hline & Bo & 60 & 147.25 & & & \\
\hline \multirow[t]{2}{*}{1978} & Yes & 203 & 127.49 & 1 & 3.12 & 0.077 \\
\hline & Do & 60 & 147.25 & & & \\
\hline \multirow[t]{2}{*}{1979} & Yes & 204 & 126.88 & 1 & 4.11 & $0.043^{*}$ \\
\hline & Bo & 59 & 149.67 & & & \\
\hline \multirow[t]{2}{*}{1980} & Yes & 225 & 130.11 & 1 & 0.96 & 0.328 \\
\hline & Ho & 38 & 143.16 & & & \\
\hline \multirow[t]{2}{*}{1981} & Yes & 225 & 130.11 & 1 & 0.96 & 0.328 \\
\hline & EO & 38 & 143.16 & & & \\
\hline \multirow[t]{2}{*}{2982} & Yes & 228 & $\$ .29 .96$ & 1 & 1.23 & 0.268 \\
\hline & so & 35 & 145.36 & & & \\
\hline \multirow[t]{2}{*}{1983} & Yes & 228 & 129.96 & 1 & 1.23 & 0.268 \\
\hline & มo & 35 & 145.36 & & & \\
\hline \multirow[t]{2}{*}{1984} & Yes & 235 & 130.51 & 1 & 0.85 & 0.358 \\
\hline & Eo & 28 & 144.50 & & & \\
\hline \multirow[t]{2}{*}{1985} & Pes & 241 & 131.21 & 1 & 0.31 & 0.578 \\
\hline & so & 22 & 140.64 & & & \\
\hline \multirow[t]{2}{*}{1986} & Yes & 247 & 129.87 & 1 & 3.19 & 0.074 \\
\hline & Ho & 16 & 164.91 & & & \\
\hline \multirow[t]{2}{*}{1987} & Yes & 251 & $13 C .51$ & 1 & 2.11 & 0.146 \\
\hline & Bo & 12 & 163.17 & & & \\
\hline
\end{tabular}

The years 1977 and 1978 had significant differences, although not statistically significant, between groups at the .10 level. Furthermore, the difference in mean days to equivalence was statistically significant at the .05 level in 1979.

Page 74 
Time to Equivalence

There appeared to be one primary reason for this finding. In an effort to meet the new regulatory requirements and stay competitive during the initial years of the 1976 amendment enactment, the medical device industry heavily recruited regulatory professionals from within the pharmaceutical industry. These individuals had experience and had an immediate impact on time to equivalence. In addition, the larger companies were more successful in their recruiting endeavors since they could afford the more talented regulatory professional. The experience which transferred from the drug environment culminated after approximately three years which resulted in a statistically significant difference in 1979.

This level of significance did not emerge again until 1986 when the number of companies inat aid not have a regulatory department declined to 16 from 60 in 1977. In addition, the mean days to equivalence from 1977 to 1985 ranged between 140 and 150 days for companies that did not have a regulatory department. However, $i-1986$, the mean days rose to nearly 165 days. This would seem to account for the significance level of .07 being detected. No industry or FDA circumstance was readily apparent during this time frame.

The null hypothesis was retained at the .05 significance level for all comparisons, except 1979. The number of days to equivalence appeared to be independent of the presence or absence of an inhouse regulatory department for all years aside from 1979. 


\section{Time to Equivalence}

Thus, companies with regulatory departments in-house produced statistically significant reductions in the time required to establish equivalence in 1979 only.

Hypothesis 2.3. There is no difference between companies who received regulatory compliance training and companies who didn't receive regulatory compliance training on time to equivalence.

Table 7 below reflects the results of testing hypothesis 2.3 by years 1977 through 1987 . 
Time to Equivalence

Table 7

Wilcoxon Scores (Rank Sums) for Variable DAYS

TO EQUIVALENCE Classified by Variable REGULATORY TRAINING

\begin{tabular}{|c|c|c|c|c|c|c|}
\hline Year & Cless & $\mathbf{B}$ & Hean & $d f$ & CBISQ & ProbschISQ \\
\hline \multirow[t]{2}{*}{1977} & Yes & 153 & 126.75 & 1 & 2.74 & 0.187 \\
\hline & Mo & : $: D$ & 139.40 & & & \\
\hline \multirow[t]{2}{*}{1978} & Yes & 155 & 126.75 & 1 & 1.74 & 0.287 \\
\hline & Bo & 110 & 139.40 & & & \\
\hline \multirow[t]{2}{*}{1979} & Yes & 189 & 124.21 & 1 & 7.04 & $0.008 *$ \\
\hline & Bo & 74 & 151.88 & & & \\
\hline \multirow[t]{2}{*}{1980} & Yes & 189 & 124.21 & 1 & 7.04 & $0.008 *$ \\
\hline & No & 74 & 151.88 & & & \\
\hline \multirow[t]{2}{*}{1981} & Yes & 210 & 128.43 & 1 & 2.30 & 0.129 \\
\hline & so & 53 & 146.16 & & & \\
\hline \multirow[t]{2}{*}{1982} & Yes & 213 & 128.29 & 1 & 2.67 & 0.102 \\
\hline & Ho & 50 & 147.81 & & & \\
\hline \multirow[t]{2}{*}{1983} & Yes & 214 & 128.35 & 1 & 2.64 & 0.104 \\
\hline & 80 & 49 & 147.92 & & & \\
\hline \multirow[t]{2}{*}{1984} & Yes & 221 & 130.59 & 1 & 0.48 & 0.490 \\
\hline & so & 42 & 139.43 & & & \\
\hline \multirow[t]{2}{*}{1985} & Yes & 226 & 131.41 & 1 & 0.10 & 0.755 \\
\hline & so & 37 & 135.62 & & & \\
\hline \multirow[t]{2}{*}{1986} & Yes & 226 & 131.41 & 1 & 0.10 & 0.755 \\
\hline & No & 37 & $\$ 35.62$ & & & \\
\hline \multirow[t]{2}{*}{1987} & Yes & 226 & 131.41 & 1 & 0.010 & 0.755 \\
\hline & no & 37 & 135.62 & & & \\
\hline
\end{tabular}

Upon review of the data regarding hypothesis 2.3 , there did not appear to be a difference in group means regarding the number of days to equivalence. It appeared that regulatory training did not have a statistically significant impact on time to equivalence. 
Time to Equivalence

The only years that did not adhere to this finding were 1979 and 1980 .

Comparing groups did yield a .008 level of significance for 1979 and 1980. It was evident that there had been a 338 decrease from 1978 to 1979 in companies who had not received regulatory training. In addition, the mean days to equivalence had increased by 88 from 1978 to 1979 for those companies with regulatory training. This pattern remained constant through 1980. From 1981 through 1987 the difference between means remained negligible.

Once again, some reasons for this occurrence resided in the industry and the agency. For the industry, the years 1977 and 1978 amounted to lead years where regulatory knowledge was being accrued at a fast rate, but with little consequence. Also, during these years, the agency was in a developmental stage with regard to whatever regulatory training that was being provided. The agency was just beginning to orient the Office of Small Manufacturers Assistance (OSMA) to the needs of the medical device manufacturer. In fact, the first article highlighting the services provided by DSMA was published in 1979. This event may partially explain the significance achieved in 1979 and 1980 .

The reduced difference from 1981 through 1987 reflected the diffusion of the body of experience that was attained during 1979 and 1980. The level of skill across the industry became diluted and a fairly homogeneous group emerged with regard to regulatory knowledge. The arrival or departure of a trained regulatory 
Time to Equivalence

professional did not have a statistically significant impact on time to equivalence from 1981 through 1987.

Therefore, days to equivalence seemed independent of regulatory training experience except in 1979 and 1980. The null hypothesis was rejected for these years only. During 1979 and 1980 , regulatory training did have a statistically significant influence on time to equivalence.

Hypothesis 2.4. There is no difference between companies who manufacture one medical device and companies that manufacture more than one device on time to equivalence.

Table 8 below reflects the results of testing hypothesis 2.4 by years 1977 through 1987. 


\section{Time to Equivalence}

Table 8

Wilcoxon Scores (Rank Sums) for Variable DAYS

TO EQUIVAJENCE Classified bY Variable MORE THAN ONE DEVICE

\begin{tabular}{|c|c|c|c|c|c|c|}
\hline Year & Clase & $\mathbf{B}$ & Mean & DF & CHISQ & Prob>caIso \\
\hline \multirow[t]{2}{*}{1977} & Yes & 216 & 124.55 & 1 & 11.61 & 0.0007 \\
\hline & 180 & 47 & 166.24 & & & \\
\hline \multirow[t]{2}{*}{1978} & Yes & 216 & 125.55 & 1 & 11.61 & 0.0007 * \\
\hline & Bo & 47 & 166.24 & & & \\
\hline \multirow[t]{2}{*}{1979} & Tee & 216 & 124.55 & 1 & 11.61 & 0.0007 \\
\hline & Eo & 47 & 166.24 & & & \\
\hline \multirow[t]{2}{*}{1980} & Yes & 237 & 127.75 & 1 & 7.49 & $0.006=$ \\
\hline & wo & 26 & 170.75 & & & \\
\hline \multirow[t]{2}{*}{1981} & YeB & 245 & 129.25 & 1 & 4.98 & $0.026 *$ \\
\hline & Do & 17 & 171.82 & & & \\
\hline \multirow[t]{2}{*}{1982} & Yes & 249 & 129.12 & 1 & 6.70 & $0.010 *$ \\
\hline & Bo & 14 & 183.21 & & & \\
\hline \multirow[t]{2}{*}{1983} & Yes & 250 & 129.58 & 1 & 5.12 & $0.024 *$ \\
\hline & no & 13 & 178.54 & & & \\
\hline \multirow[t]{2}{*}{1984} & Yes & 254 & 130.59 & 1 & 2.56 & 0.109 \\
\hline & Bo & 9 & 171.89 & & & \\
\hline \multirow[t]{2}{*}{1985} & Yes & 255 & $130 \cdot 35$ & 1 & 3.94 & 0.047 \\
\hline & Bo & 8 & $=84.56$ & & & \\
\hline \multirow[t]{2}{*}{1986} & Yes & 259 & 130.97 & 1 & 5.12 & 0.077 \\
\hline & No & 4 & 198.62 & & & \\
\hline \multirow[t]{2}{*}{1987} & Yes & 260 & 130.91 & 1 & 4.72 & 0.030 \\
\hline & Ho & 3 & 226.83 & & & \\
\hline
\end{tabular}

Table 8 indicates inat there was a difference at the .10 level between groups for all years investigated. In fact, that difference was very apparent from 1977 through 1983 where the significance 
Time to Equivalence

level was .05 or better. Years 1984 and 1986 were the only exceptions to that finding.

The difference between means and the decline in the number of companies manufacturing only one device was noteworthy. From 1977 through 1979 the average difference in means was 42 days while the number of companies manufacturing only one device remained constant at 47 . In 1980, the number of companies who reported manufacturing only one device declined by 458 to 26 ; however, the difference in means rose only 28 to 43 days.

This observed decline in companies manufacturing only one device, minimal change in mean day differences, and decline in significance level was also observed in 1981 and 1983. In 1982, the significance level again rose to 0.009 which seemed to be explained by an increase in time to equivalence over 1981 for companies manufacturing only one device.

In 1984, there was a decline in days to equivalence for companies manufacturing one device and a slight increase for those manufacturing more than one device; thus, the reason for the attainment of a non-significant level. In 1986, no decline was seen, however. The achieved significance level of 0.078 may be explained by the small sample size during this year. Aithough 1987 also had a small sample size, the increase in days to equivalence for companies manufacturing one device was much more pronounced when compared to 1986 ( 128 vs. 78).

Throughout the years 1977 - 1987, the range of days to 
Time to Equivalence

equivalence for companies manufacturing more than one device was 124 in 1977 to 131 in 1987 . However, the range for companies manufacturing only one device was 166 days in 1977 to 226 days in 1987.

Another agency perspective which provided insight to the attained significance levels in 1984 and 1986 was the introduction of more stringent regulatory requirements during 1984 and 1986. The Medical Device Reporting (MDR) law was put into effect in late 1984. This law required all companies to report all device defects which may have had añ adve:se effect on the health and safecy of the patient. Never before had such reporting been required nor in such a structured manner nor with such striking consequence. The anticipation and enactment of such a law may have neutralized any difference in days to equivalence for the two groups for this comparison.

Thus, the null hypothesis was rejected at the .05 level for all years other than 1984 and 1986. The number of days to equivalence was dependent on the number of devices a firm manufactures. The company characteristic of manufacturing one device versus manufacturing more than one device did seem to have an impact on time to equivalence over time. Those companies that manufactured more than one device accumulated fewer days of time to equivalence as compared to companies who manufactured only one device.

Hypothesis 2.5. There is no difference between companies who 
Time to Equivalence

report using regulatory affairs consultants and companies that don't use regulatory affairs consultants on time to equivalenc-.

Table 9 below reflects the results of testing hypothesis 2.5 by years 1977 through 1987.

\section{Table 9}

Wilcoxon Scores (Rank Sums) for Variable DAYS

TO EQUIVALENCE Classified by Variable REGITAATORY CONSULTANT USE

\begin{tabular}{|c|c|c|c|c|c|c|}
\hline Year & Class & $\mathbf{x}$ & Mean & $d f$ & CHISQ & Prob $>$ CHISC \\
\hline \multirow[t]{2}{*}{1977} & Yes & 142 & 122.15 & 1 & 5.71 & 0.020 \\
\hline & so & 121 & 143.55 & & & \\
\hline \multirow[t]{2}{*}{1978} & Yes & 145 & 121.61 & 1 & 6.02 & $0.014^{*}$ \\
\hline & 180 & 118 & 144.57 & & & \\
\hline \multirow[t]{2}{*}{1979} & Yes & 147 & 120.83 & 1 & 7.17 & 0.007 \\
\hline & so & 116 & 146.14 & & & \\
\hline \multirow[t]{2}{*}{1980} & Yes & 178 & 128.38 & 1 & 1.24 & 0.264 \\
\hline & Wo & 85 & 139.58 & & & \\
\hline \multirow[t]{2}{*}{1981} & Yes & 186 & 131.00 & 1 & 0.11 & 0.742 \\
\hline & Ho & 77 & 134.40 & & & \\
\hline \multirow[t]{2}{*}{1982} & Yes & 189 & 130.80 & 1 & 0.16 & 0.685 \\
\hline & s5o & 74 & 135.04 & & & \\
\hline \multirow[t]{2}{*}{1983} & Yes & 177 & 128.99 & 1 & 0.85 & 0.357 \\
\hline & Eo & 86 & 138.19 & & & \\
\hline \multirow[t]{2}{*}{1984} & Yes & 155 & 123.72 & 1 & 4.47 & 0.034 \\
\hline & Bo & 108 & 143.88 & & & \\
\hline \multirow[t]{2}{*}{1985} & Yes & 126 & 129.45 & 1 & 0.30 & 0.586 \\
\hline & no & 137 & 134.45 & & & \\
\hline \multirow[t]{2}{*}{1986} & Yes & 129 & 131.60 & 1 & 0.007 & 0.933 \\
\hline & Bo & 134 & 232.28 & & & \\
\hline \multirow[t]{2}{*}{1987} & YeB & 129 & 131.60 & 1 & 0.007 & 0.933 \\
\hline & Do & 234 & 132.38 & & & \\
\hline
\end{tabular}

Page 83 
Time to Equivalence

From 1977 to 1982 the use of regulatory affairs consultants was on the incline. From 1983 to 1987, the use of consultants declined.

From 1977 to 1980 a statistically significant difference was found to exist between groups at the .05 level. This significance level progressively declined from isô cirrough 198\%, when consultant use was the highest. In 1984, when consultant use started to balance out with non-use, a statistically significant difference $(p>0.05)$ was detected again. However, as the discrepancy between use and non-use diminished from 1985 through 1987, so did the difference in days to equivalence.

Patterns which emerged within the industry and agency as expressed earlier were seen here as well. In an effort to stay competitive within the newly regulated marketplace, the medical aevice manufacturer brought in outside regulatory consultants from 1977 through 1982. This newly instituted workforce had a statistically significant impact on time to equivalence in 1977. This influence increased from 1978 through 1979. In 1979, where the greatest significance level was attained, it was apparent that the use of outside regulatory consultants was producing a profound impact on time to equivalence.

As seen before, once the industry acquired internal regulatory expertise through training and new employees, use of consultants was less influential. After 1979, FDA was perfecting its training programs and dissemination of information. Although consultant use 
Time to Equivalence

did not decline from 1980 through 1983, no statistically significant difference in time to equivalence was detected. This lack of significance was possibly due to consultant activities devoted to keeping up with more stringently imposed older regulations. Whereas, in 1984, when significance was seen again, consultant use, although on the decline, was being applied in response to new regulations (e.g., MDR law).

In conclusion, it seemed apparent that early (1977 - 1979) consultant use may have contributed to reduced days to equivalence. Albeit, as the number of days to equivalence increased and consultant use declined, the impact on time to equivalence was less measurable. In other words, early differences in time to equivalence may have been dependent on use of regulatory affairs consultants. The more recent trend, however, indicated that days to equivalence was independent of consultant use.

Thus, the null hypothesis was rejected at the .05 level of significance for years 1977 - 1979 and 1984 .

\section{Research Question Number 3}

Is there a any difference between time to equivalence and respondent's (company's) attitudes about selected characteristics of the regulatory process as having an impact on time to equivalence? 
Time to Equivalence

Since the assumptions of normaility for an ANOVA were not met for this research question, hypotheses 3.1 through 3.5 were tested via the Rruskal-Wallis test. Tables 10 - 14 supply information related to these tests.

In Tables 10 - 14, the comparison between groups reflecied information related to classes or levels of the independent variable. Class 1 equals "Strongly Agree". Class 2 equals "Agree". Class 3 equals "No Opinion". Class 4 equals "Disagree". Class 5 equals "Strongly Disagree".

Hypothesis 3.1. There is no difference between the companies who perceive FDA written communication as having an impact on timely compliance and companies that don't perceive FDA written communication as having an impact on timeiy compiiance on time to equivalence.

Table 10 highlights the results of testing hypothesis 3.1 . 
Table 10

Wilcoxon Scores (Rank Sums) for Variable DAYS

TO EQUIVALENCE Classitied by Variable ATTITUDE

TOWARD WRITPEN COMGUNICATION WITH FDA

Class N Mean Score

\begin{tabular}{lcc}
\hline \hline & 22 & 161.20 \\
Strongly Agree & 137 & 116.64 \\
Agree & 5 & 131.50 \\
No Opinion & 94 & 143.69 \\
Disagree & 5 & 205.10 \\
Strongly Disagree & 5 Chi-Square Approximation) \\
Rruskal-Wallis Test & (ChisQ=0.003
\end{tabular}

Since the calculated value of the test statistic exceeded the critical value at the 0.003 level, there was a statistically significant difference between the various levels of agreement regarding written communication with FDA and time to equivalence.

The null hypothesis was rejected. In conclusion, the difference in average days to equivalence for the five levels of agreesuent regarding written communication with the FDA was statistically significant at the 0.003 level. There was a difference in meen days to equivalence between companies who perceived written communication with FDA as having an impact on timely compliance and companies who did not perceive written 
Time to Equivalence communication with FDA as having an impact on timely compliance. Review of Table 10 indicated that those respondents who agreed that written communication with FDA impacted time to equivalence had the lowest mean time to equivalence (116 days) and the greatest number of respondents $(n=137)$. The next highest group of respondents $(n=94)$ disagreed with the tenet that written communication impacted time to equivalence and their mean time to equivalence was 131 days. Those respondents who sirrongiy disagreed with the influence of written communication had the highest mean value of 205 days to equivalence. It was interesting to note that those respondents who strongly agreed with this influence had the second highest mean time to equivalence (161 days). This may indicate that extensive written communication with FDA results in delays associated with numerous channels of communication, interfacing review bodies, bureaucratic levels, and the logistics of generating and logging official communications with FDA.

Hypothesis 3.2. There is no aifference between companies who perceive FDA oral communication as having an impact on timely compliance and companies that don't perceive FDA oral communication as having an impact on timely compliance on time to equivalence.

Table 11 highlights the results of testing hypothesis 3.2 . 
Table 11

Wilcoxon Scores (Rank Sums) for Variable DAYS
TO EQUIVALENCE Classified by Variable ATTITUDE TOWARD ORAL COMMUNICATION WITH FDA

Class N Mean Sccre

\begin{tabular}{lcc}
\hline & 28 & 160.05 \\
Strongly Agree & 154 & 129.00 \\
Agree & 5 & 118.90 \\
No Opinion & 76 & 128.60 \\
Disagree & 0 & 000.00 \\
Strongly Disagree & (Chi-Square Approximation) \\
Rruskal-Wallis Test & df=3 Prob > CHIsQ = 0.226
\end{tabular}

Since the calculated value of the test statistic did not exceed the critical value at the 0.05 level, there was no measurable difference between the different leveis of agreement regarding oral communication with FDA and time to equivalence.

Although over 698 of the respondents were of the opinion that oral communication with FDA did impact time to equivalence, there did not appear to be a statistically measurable difference in time to equivalence. It was noteworthy that those individuals who disagreed with this hypothesis had second lowest mean value. In addition, those respondents with no opinion about this influence on time to equivalence had the lowest mean days. This finding was 
Time to Equivalence

difficult to assess due the low number of respondents in this categery.

The null hypothesis was retained. Thus, the difference in average days to equivalence for the five levels of agreement regarding oral communication with the FDA was not statistically significant different at the 0.05 level. There was no statistically significant difference in mean days to equivalence between those companies who perceived oral communication with FDA has having an influence on timely compliance and those companies who did not perceive oral communication as having an impact on timely compliance.

Hypothesis 3.3. There is no difference between companies who perceive the Office of Small Manufacturers Assistance (OSMA) regulatory compliance training as having an impact on timely compliance and companies who don't perceive the OSMA regulatory compliance training as having an impact on timely compliance on time to equivalence.

Table 12 has the results of testing hypothesis 3.3 . 
Table 12

Wilcoxon Scores (Rank Sums) for Variable DAYS

TO EQUIVAIENCE Classified by Variable ATTITUDE

TOWARD REGULATORY TRAINING

Class N Mean Score

$\begin{array}{lcc}\text { Strongly Agree } & 27 & 137.05 \\ \text { Agree } & 158 & 128.99 \\ \text { No Opinion } & 24 & 125.77 \\ \text { Disagree } & 53 & 141.34 \\ \text { Strongly Disagree } & 1 & 125.00 \\ \text { Rruskal-Wallis Test (Chi-Square Approximation) } & \text { (CHISQ = 1.335 df=4 Prob > CHISQ = } 0.855\end{array}$

Since the calculated value of the test statistic did not exceed the critical value at the 0.05 level, there was no statistically measurable difference between the various levels of agreement regarding regulatory training experience and time to equivalence.

Again, the majority of the respondents (708) agreed that regulatory training did impact time to equivalence, but the difference in mean values were not statistically significant. The highest mean values were recorded for those respondents who were of the opinion that regulatory training did not impact time to equivalence (141 days). 
Time to Equivalence

Due to the large number of respondents $(n=24)$ who had no opinion about this influence, a $2 \times 3$ contingency table was generated. A dichotomous category of agree and disagree was crosstabulated with three levels of days (i.e., 0-50, 50-100, and greater than 100 days). Those respondents with no opinion were collapsed into the disagree categcry to assure a conservative interpretation of the results. Table 13 presents the results of that crosstabulation. A non-significant result was achieved for this test of difference between the observed number and the expected number of responses.

\section{Table 13}

Crosstabulation of Variable DAYS TO EQUIVALENCE

by Variable ATTITUDE TOWARD REGULATORY TRAINING

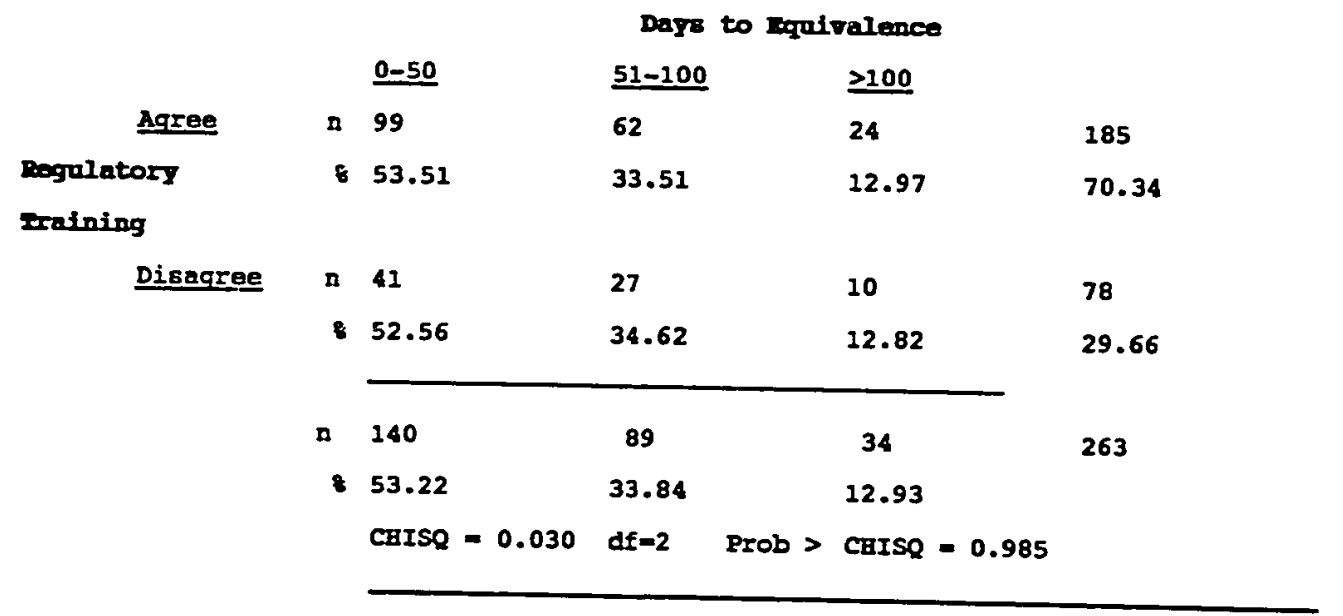

Page 92 
Time to Equivalence

The null hypothesis was retained. In conclusion, the difference in average days to equivalence for the five levels of agreement regarding regulatory training was not statistically significant at the 0.05 level. The collapsed crosstabulation was also not significant at the 0.05 level. It was apparent that the difference in time to equivalence was not statistically significani with regard to opinions related to regulatory training. Consequently, there was no statistically significant difference in mean days to equivalence between companies who perceived OSMA regulatory training as haring an influence on timely compliance and companies who did not perceive OSMA regulatory training as having an influence on timely compliance.

Hypothesis 3.4. There is no difference between companies who perceive having an in-house regulatory department as having an impact on timely compliance and companies who don't perceive having an in-house regulatory department as having an impact on timely compliance on time to equivalence.

Table 14 highlights the results of testing hypothesis 3.4 . 


\section{Time to Equivalence}

Table 14

Wilcoxon Scores (Rank Sums) for Variable DAYS

TO EQUIVALENCE Classified by Variable

ATIITUDE TOWARD AN IN-HOUSE REGULATORY DEPARTMENT

Class N Mean Score

\begin{tabular}{lcc}
\hline Strongly Agree & 82 & 127.15 \\
Agree & 174 & 134.53 \\
No Opinion & 6 & 118.25 \\
Disagree & 1 & 171.50 \\
Strongly Disagree & 0 & 000.00 \\
Rruskal-Wallis Test (Chi-Square Approximation) & \multicolumn{3}{c}{ (CHISQ = 0.993 df=3 Prob > CHISQ = 0.803}
\end{tabular}

Since the calculated value of the test statistic did not exceed the critical value at the 0.05 level, there was no statistically significant difference between the various levels of agreement regarding the presence or absence of an in-house regulatory affairs department and time to equivalence.

Although 978 of the respondents agreed that an in-house regulatory department impacts time to equivalence, no difference in means was apparent. It was notable that there was a large difference in mean days to equivalence between those that agreed and those that disagreed. However, the small number of respondents who disagreed $(n=1)$ made this comparison questionable. 
Time to Equivalence

The null hypothesis was retained. In conclusion, the difference in average days to equivalence for the five levels of agreement regarding in-house regulatory departments was not statistically significant at the 0.05 level. That is, there was no statistically significant difference in mean days to equivalence between companies who perceived the presence of an in-house regulatory department as having an influence on timely compliance and companies who did not perceive having an in-house regulatory department as having an influence on timely compliance.

Hypothesis 3.5. There is no difference between companies who perceive the use of outside regulatory affairs consultants as having an impact on timely compliance and companies that don't perceive the use of outside regulatory affairs consultants as having an impact on timely compliance on time to equivalence.

Table is highlights the results of testing hypothesis 3.5 . 


\section{Time to Equivalence}

Table 15

Wilcoxon Scores (Rank Sums) for Variable DAYS

TO EQUIVALENCE Classified by Variable ATTITUDE

TOWARD REGULATORY CONSULTANT USE

Class N Mean Score

\begin{tabular}{lcc}
\hline \hline & 4 & 138.55 \\
Strongly Agree & 158 & 123.34 \\
Agree & 64 & 131.48 \\
No Opinion & 16 & 177.44 \\
Disagree & 21 & 162.88 \\
Strongly Disagree & df=4 Prob > CHISQ = 0.024 \\
Rruskal-Wallis Test (Chi-Square Approximation) \\
\multicolumn{1}{c}{ CHISQ = 11.25 }
\end{tabular}

Since the calculated value of the test statistic exceeded the critical value at the 0.05 level, there was a statistically significant difference between the various levels of agreement regarding the use of outside regulatory affairs consultants and time to equivalence.

Only 618 of the respondents agreed that time to equivalence was impacted by use of outside regulatory consultants. Thirty-one percent were of no opinion and 88 of the respondents disagreed. The a erage mean value for those that agreed was 130 days. The average mean value for those that $d i s=g r e e d$ was 166 days.

Page 96 
Time to Equivalence

As with hypothesis 3.3, a large portion of the respondents were of no opinion regarding this influence on timely compliance. A $2 \times 3$ contingency table was generated again with the no opinion responses being collapsed into the disagree category. Table 16 highlights the results of this analysis. Although the chi-square statistic was not statistically significant at the 0.05 level, it was notable that the percentage of respondents who disagreed with this influence was twice that of those that agreed when beyond 100 days to equivalence, 18.818 and $9.26 \%$, respectively. This nonsignificant finding may be attributed to the conservativeness of coilapsing the no opinions into the disagree category.

\section{Table 16}

Crosstabulation of Variable DAYS TO EQUIVALENCE

by Variable ATTITUDE TOWARD REGULATORY

CONSULTANT USE

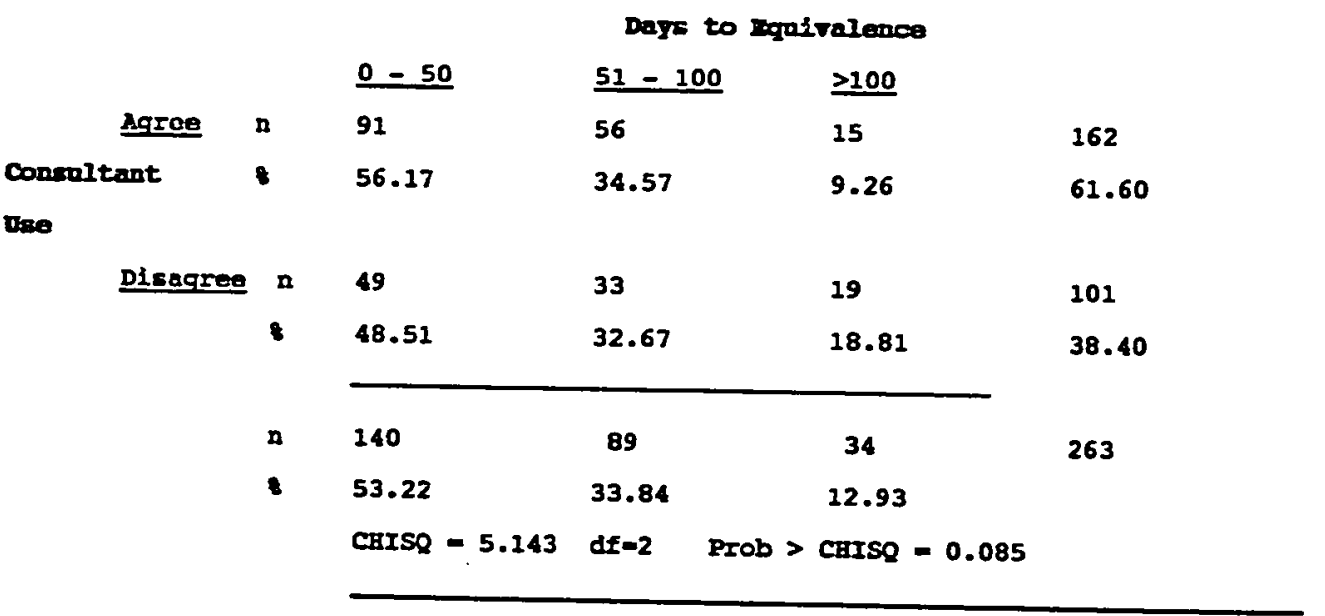

Page 97 
Time to Equivalence

Based on the Rruskal-Wallis test statistic, the null hypothesis was rejected. In conclusion, the differencs in average days to equivalence for the five levels of agreement regarding use of regulatory affairs consultants was stetistically significant at the 0.05 level. Thus, there was a statistically significant difference in mean days to equivalence between companies who perceived the use of outside regulatory consultants as having an impact on timely compliance and companies who did not perceive the use of outside regulatory consultants as having an impact on timely compliance.

\section{Research Question Number 4}

What combination of independent variable measures best predicts time to equivalence?

The testing of research question number 4 involved looking at combined independent variables and how those combinations predicted time to equivalence. Up to this point concentration had been on predicting time to equivalence based on the following independent variables: number of years manufacturing medical devices, number of employees in the organization, and number of employees in the regulatory department. The question still remained as to what other variables may have also effected time to equivalence. Since this model involved multiple independent variables, a muitiple regression prediction equation with convericed beta weights were 
Time to Equivalence

calculated.

There were twelve independent variables in this equation, $x_{1} \ldots x_{12}$. They were the following: number of years manufacturing medical devices (YEARS), number of employees in the organization in 1987 (EMPO87), presence or absence of a regulatory department in 1987 (REG87), number of employees in that regulatory department in 1987 (EMPR87), regulatory training experience in 1987 (TRN87), number of devices manufactured in 1987 (DEV87), use of regulatory consultants in 1987 (CON87), opinion about the impact on time to equivalence with regard to oral communication with FDA (OCCMM): written communication with FDA (WCOMM), regulatory training (TRAIN), in-house regulatory department (INREG), and outside regulatory consultants (OUTREG). The following estimated regression prediction equation was formulated:

$$
y=b_{1} x_{1}+b_{2} x_{2}+\ldots b_{12} x_{12}
$$

where $b_{1}, b_{2} \ldots b_{12}$ estimate the regression coefficients $B_{1}$, $B_{2} \ldots B_{12}$.

Table 17 below highlights the results of this test. 
Table 17

Model Relating Variable DAYS TO EQUIVALENCE to

Multiple Independent Variables

Multiple $\mathrm{R}=.787$

Variable df Beta Weights p-value

\begin{tabular}{|c|c|c|c|}
\hline IEARS & 12 & -0.261 & 0.146 \\
\hline BNPO87 & 12 & 0.113 & 0.413 \\
\hline EMPR87 & 12 & 0.001 & 0.987 \\
\hline REG87 & 12 & -0.213 & 0.207 \\
\hline TRAB & 12 & -0.036 & 0.863 \\
\hline DEV87 & 12 & 0.109 & 0.506 \\
\hline Coss & 12 & -0.392 & 0.115 \\
\hline ocary & 12 & 0.652 & 0.021 " \\
\hline reOMr & 12 & 0.097 & 0.718 \\
\hline TRAIN & 12 & -0.242 & 0.123 \\
\hline IXREG & 12 & 0.176 & 0.559 \\
\hline OOTREG & 12 & 0.701 & $0.001 *$ \\
\hline
\end{tabular}

Table 17 represents the calculated beta weights and significance levels for each variable. The beta weights were then inserted into the multiple regression prediction equation as displayed below. The beta weights indicated which variables contributed the most to the prediction of days to equivalence, the dependent variable. The equation was:

DAYS TO EQOTVALEXCB $=-0.261$ (YRARS) +0.113 (RMPO8?) +

0.001 (EMPR87) $+-0.213($ REG87) $+-0.036($ TRRB7) +0.109 (DEVB7) +

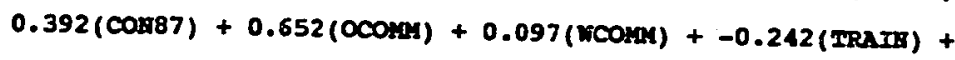

0.176 (IARRG) +0.701 (OUIREG).

Page 100 
Time to Equivalence

The numbers in the equation are interpreted as follows:

$b_{1}=-0.261$ was the estimate of the relative prediction weight for the variable YEARS MANUFACTURING MEDICAL DEVICES.

$b_{2}=0.125$ was the estimate of the relative prediction weight for the variable NUMBER OF EMPLOYEES IN THE ORGANIZATION.

$b_{3}=0.001$ was the estimate of the relative prediction weight for the variable NUMBER OF EMPLOYEES IN THE REGULATORY DEPARTMENT.

$b_{4}=-0.392$ was the estimate of the relative prediction weight for the variable IN-HOUSE REGULATORY DEPARTMENT.

Estimates were supplied for the remaining population parameters $\left(b_{5} \ldots b_{12}\right)$ as indicated in the equation above.

of importance were the relative prediction values and significance probabilities for the twelve estimates in the multiple regression prediction equation. The relative prediction values indicated which prediction variables contributed the most to successful prediction. The significance probabilities (p-values) indicated if the predictor variables were significantly different from zero. 
Time to Equivalence

Review of Table 17 indicates that the respondent's perceived influence of outside consultant use on timely compliance and the influence of oral communicatinn with IDA on timely compliance were the best relative predictors of days to equivalence. Actual use of outside regulatory consultants and number of years manufacturing medical devices appeared to be secondary contributors to the successful prediction of days to equivalence.

The significance probabilities for the respendent's attitudes toward use of outside regulatory consultants and oral communication with FDA gave adequate evidence of the statistically significant effect of these variables on predicting time to equivalence. Furthermore, the p-value at the 0.05 level indicated with $95 \%$ confidence that these particular predictor variables assist in decreasing the difference between the predicted and actual criterion scores.

In conclusion, two of the twelve variables were primary contributors to successful prediction and two additional variables may be considered secondary contributors to successful prediction. Opinions about the impact of oral communication with FDA on time to equivalence and opinions about the impact of outside regulatory consultant use on time to equivalence seemed to best predict time to equivalence. Actual use of outside regulatory consultants and the number of years a company has been manufacturing medical devices were secondary predictors of time to equivalence.

Page 102 
Time to Equivalence

Some suggested conclusions were: 1) regulatory managers who perceive outside consultant use as being influential on time to equivalence may expect to have lower mean days to equivalence than those managers who disagree with this perception in light of the results of testing hypothesis 3.5 ; 2) regulatory managers who believe that oral communication with FDA does influence timely compliance may expect higher mean days to equivalence than those managers that do not agree with this tenet in light of the results of testing hypothesis 3.2 .

\section{Research Question Number 5}

What variables appear to have an impact on time to equivalence as perceived by the company respondent? This research question relates to questions number 4 and 10 on the questionnaire.

Respondents were asked in Question Number 4 their opinion about the influence of the FDA review process on production costs. Approximately half (54.7\%) of the respondents stated that production costs were influenced by the FDA review process. When examining this same variable within specified subgroups, this same distribution was approximated. For example, among companies manufacturing more than one device in 1987, 548 stated there was an influence on production costs. For companies who received regulatory training in 1987, the percentage was 548. For companies who had regulatory departments in 1987, it was 518. However, among 
Time to Equivalence companies who employed regulatory consultants in 1987, 768 stated production costs were influenced by the review process. Whereas, among companies who did not use outside consultants, only 348 felt production costs were influenced by the review process.

As a result, for the study group as a whole and within many subgroupings, opinions were evenly divided with regard to the influence of the FDA review process on production costs. However, companies that were subgrouped by outside consultant use did not follow this pattern. Although companies using outside regulatory consultants benefited from this utilization, (i.e., less time to equivalence in years immediately following the enactment of a new regulation - Hypothesis $\# 2.5$ ), it seemed apparent that it was the opinion of companies using outside regulatory consultants that production costs were impacted by the FDA review process. In contrast, many of the companies that did not use outside consultants, did not feel production costs were influenced by the review process.

With regard to Question Number 10 on the survey, 818 of the respondents indicated other things or entities which were not directly addressed on the questionnaire that may impact time to equivalence. Table 18 below lists those responses and the percentage of respondents who emphasized them. 
Time to Equivalence

Table 18

Frequency Distribution of Entities

Impacting Variable TIME TO EQUIVAIENCE

Response

Percent

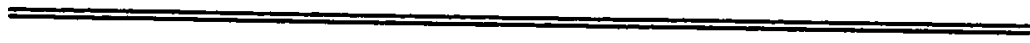

1) Changing Regulations 26

2) Changes in FDA Policy 10

3) Lawyers and FDA Review Panel 10

4) Limited FDA Staff 10

5) Properly Prepared Submissions 10

6) Lack of FDA Funding 4

7) Pre-clinical Expertise 4

8) FDA Budget Problems 4

9) Rapport with FDA 3

10) Device Complexity 2

11) Other 12

11a) FDA Overload Total $=100$

11b) R \& D Quality

11c) FDA Reviewer's Rnowledge Level

11d) Binder Quality

11e) Political Pressure on FDA 
Time to Equivalence

SUMMARY

The chapter presented results on the impact of federal social regulations upon the time required to establish equivalence for a medical device within the orthopaedic medical device industry. Means and standard deviations for time to equivalence within specified subgroups were calculated. Comparisons of means related to company characteristics were made. Regression coefficients and Kruskal-Wallis chi-square statistics were calculated. Most relevant results of these computations are summarized in the following paragraphs.

\section{Research Question One}

A total of two hundred and sixty three responses was included in the data analysis. The impact of federal social regulations upon time to equivalence was examined by regressing three independent variables on one dependent variable, time to equivalence.

The first independent variable was the number of years a company had been manufacturing medical devices. This impact was in a negative direction. A statisticaliy measurable difference was detected at the 0.05 level. A relationship was found to exist between the number of years manufacturing and time to equivalence. As the number of years a company manufactured medical devices increased, there was a predictable decrease in the amount of time required to get a medical device through the FDA review process and 
Time to Equivalence

establish equi llence.

The secor ^ independent variable was the number of employees in the organization. The relationship of this variable with time to equivalence was evaluated over time from 1977 to 1987 . A positive relationship was found to exist from 1978 through 1982 . As the number of employees in a company increased, so did the number of days required to established equivalence during these years.

A statistically significant difference was ascertained at the 0.05 level from 1978 through 1982, while no predicable relationship seemed to exist in 1977, nor from 1983 through 1987. The reason for this pattern possibly rests with the combined response of FDA and industry to the enactment of the 1976 Medical Device Amendments. This represented a maturation process which evolved over time.

The third independent variable was the number of employees in the regulatory department. This relationship was also evaluated over time. No statistically significant difference was achieved for any year from 1977 through 1987. Although no statistically significant difference was apparent, however, the number of employees in the regulatory department did seem to have a negative impact on time to equivalence.

\section{Research Question Two}

The impact of epcoified company characteristics on time to equivalence was examined. Five independent variables were measured. 
Time to Equivalence Those variables or characteristics were: class of device manufactured, in-house regulatory department, regulatory training, number of devices manufactured, and use of out-of-house regulatory consultants. All variables, but class of device, were evaluated over time, 1977 through 1987. A total of 263 responses were included in the data analysis.

For the first independent variable, class of device based on the associated degree of risk, the chi-square statistic was not statistically significant at the 0.05 level. In other words, time to equivalence seemed to be independent of the class of device manufactured.

For the second independent variable, in-house regulatory department, the chi-square statistic was found to be statistically significant at the 0.05 level in 1979 only. Time to equivalence was impacted by the presence of an in-house regulatory department in 1979, but not from 1977 through 1978, nor from 1980 througin 1987. The third independent variable, regulatory training, was found to impact time to equivalence in 1979 and 1980 only. The chisquare statistic revealed a statistically measurable difference in time to equivalence for these years, but not from 1977-1978, nor 1981 through 1987. Thus, those companies who received regulatory training in 1979 and 1980 were found to have a difference in time to equivalence at the 0.05 significance level as compared to companies who did not experience regulatory training in 1979 and 1980 . 
Time to Equivalence

The fourth independent variable, number of medical devices manufactured, influenced time to equivalence for all years except 1984 and 1986. The chi-square statistic detected a statistically measurable difference at the 0.05 level in time to equivalence for all years but 1984 and 1986. Aside from 1984 and 1986, companies who manufactured more than one device required notably fewer days to establish equivalence than companies that manufactured only one device.

For the fifth independent variable, use of an outside regulatory consultant had a statisticaliy significant impact on time to equivaience from 1977 through 1979, and then again in 1984 . No difference was detected from 1980 through 1983, nor after 1984 . The chi-square statistic was statistically significant at the 0.05 level for 1977, 1978, 1979, and 1983 only. Time to equivalence seemed to be dependent on outside consultant use for these years alone.

\section{Research Question Three}

Respondents attitudes about selected attributes of the regulatory process and their impact on time to equivalence were examined. There were 263 responses in the data analysis. Five attributes or independent variables were specified. They were the following: oral communication with FDA, written communication with FDA, regulatory training, in-house regulatory department, and outof-house regulatory consultant use. 
Time to Equivalence

The chi-square statistic was statistically significant at the 0.05 level for written communication with FDA and use of outside consultants only. No statistically significant difference in class means was detected for oral communication with Fnx. regulatory training, nor in-house regulatory department.

Thus, mean values for those respondents who agreed that written communication and use of outside consultants impacts time to equivalence were statistically different from those respondents who disagreed with this tenet. Mean values were significantly lower for the respondents who agreed. One reason for this finding may be the association of regulatory professionals with regulatory compliance. Companies who introduce regulatory professional consultants into their organization also introduce increased compliance activities (i.e., documentation, record keeping, quality control,). FDA inspection is eminent if compliance activities are not documented and submitted to FDA. In concert, FDA review of medical devices for substantial equivalence is facilitated and possibly reduced in time if the agency's requirements are fully met on the first submission.

However, the above results were suspect based upon the measurement process. There was some concern with the reliability of the measurement device relative to the design of the question items on the questionnaire. Although the coefficient of stability was satisfactory, the test-retest reliability process had a small number of participants $(n=4)$. Additionally, questions $\# 5$ - *9 
Time to Equivalence

provided possible evidence for the primacy effect. Items presented early in the list of options were disproportionateiy likely to be cited among the favored options. Consequently, Questions $\# 5$ - 9 may not have elicited reliable answers.

\section{Research Question Four}

The impact of federal social regulations on time to equivalence was measured by evaluating the combined influence of all independent variables differentiated in Research Questions One through Three. A total of two hundred and sixty three responses was included in the analysis. This equation was formulated to determine which population parameters which were converted to beta weights best predicted time to equivalence.

The multiple regression prediction equation produced beta weight estimates which were statistically significant at the 0.05 level for the opinions about oral communication with FDA and opinions about use of outside regulatory consultants. Thus, as opinions about oral communication with FDA and its impact on time to equivalence shifted from agreeing to disagreeing, there was a corresponding increase in days to equivalence. And, as opinions about outside consultant use and its impact on time to equivalence shifted from agreeing to disagreeing, there was a predictable increase in days to equivalence. 
Time to Equivalence

\section{Research Question Five}

This descriptive analysis accumulated respondent's comments about eciditional things not directly addressed on the survey questionnaire which the respondent thought influences time to equivalence. A total of 263 responses was included in the analysis.

Eighty one percent $(n=213)$ of the respondents provided additional entities which they thought impacted the time required to get a medical device through the review process and onto the market. Sixteen general categories were referenced by the respondents. The respondents noted changing regulations as impacting time to equivalence most often (26\%). The bulk of the other comments were represented by the following categories: changing FDA policy, lawyers and FDA review panel, limited FDA staff, and properly prepared submissions. 
Time to Equivalence

Chapter $\mathbf{V}$

SUMMARY, CONCLUSIONS, AND RECOMENDATIONS

This chapter presents an overview of the study on federal social regulations' impacts on time to equivalence in the orthopaedic medical device industry. The first section is a review of preceding chapters, including discussion of the research problem and approach, summary of relevant research literature, method, and findings. The conclusion section relates findings to selected literature, eraluates the research and discusses its implications. The final section makes recommendations for future study.

\section{Summary}

\section{The Research Problem}

Research was conducted to evaluate federal social regulations and their impact upon the time required to get a medical device through the FDA review process and onto the market. Government regulation of business can be divided into two basic categories: economic and social. The purpose of the study was to investigate the degree and nature of impact, due to compliance with different categories of the 1976 Medical Device Amendment, on the $\pm i m s \pm 0$ equivalence for companies with specified characteristics and as perceived by the company's regulatory affairs manager. 
Time to Equivalence

Specifically, the research was designed to answer the following research questions:

1. What is the relationship between time devoted to establishing an FDA disposition of substantial equivalence for an orthopaedic medical device and related costs and resource consumption?

2. Is there any difference between respondents (companies) who possess or do not possess certain identified characteristics and time required to establish equivalence?

3. Is there a any difference between time to equivalence and respondent's (company's) attitudes about selected characteristics of the regulatory process as having an impact on time to equivalence?

4. What combination of independent variable measures best predicts time to equivalence?

5. What variables appear to have an impact on time to equivalence as perceived by the company respondent?

\section{The Research Approaches}

\section{Approach I}

The first level of analysis dealt with Research Question Number 1. The research approach was a descriptive-correlational survey. Its purpose was to determine the relationship between three characteristics of the orthopaedic medical device manufacturing company and time to equivalence. 
Time to Equivalence

\section{Approach II}

The second phase of the analysis addressed Research Questions 2 and 3. This analysis compared 2 to 5 levels of 10 independent variables with one independent variable, time to equivalence. Since all comparisons involved two or more groups and did not meet the assumptions associated with one-way analysis of variance (ANOVA), the non-parametric analogue Rruskal-Wallis Test was utilized to detect differences between groups or independent variable levels.

\section{Approach III}

The third method involved the development of a multiple regression prediction equation with regression coefficients and beta weights for all study variables on time to equivalence. This was done in an effort to detect which variables best predicted time to equivalence.

\section{Approach IV}

This fourth level of analysis was primarily descriptive. It addressed information suppiied through questions 4 and 10 on the questionnaire. These questions requested the respondent supply opinion information. This yielded data which was qualitative in nature and nominal on type.

\section{Criteria for Data Sources}

Several criteria were used to select data sources and include the following: 
Time to Equivalence

Criteria 1. Documents have to be related to orthopaedic medical device firms in the United States.

Criteria 2. Selected device categories have no less than ten devices manufactured between 1976 and 1988 .

Criteria 3 . Selected firms have a regulatory affairs department and manager or some person responsible for regulatory affairs.

Criteria 4. The person within each firm to whom the request for data was addressed was the regulatory affairs manager or person responsible for filing $510(k) s$.

\section{Review of Selected Literature}

The role of government had been primarily to support the business system in its role of economic leadership and to mediate between business and society. Government's role had changed from judging how well business performed its social responsibilities to defiring what these responsibilities should be. The role of government was enlarged to include a regulatory function. A wave of legislative regulation of business followed. The rapid expansion of government controls had been associated with a growing dissatisfaction with the affects of regulations.

Two widely accepted divisions of federal government regulation were economic and social regulation. Government's basic reform strategy had animated the growth of federal protective regulatory programs and had created a series of regulatory agencies, all for the purpose of bettering and improving, both socially and 
Time to Equivalence

economically, the operation of business and industry. Both types of regulations cost, as well as benefit, industry and society. Weidenbaum (1977) identified expansions of social regulations, particularly the six areas of job safety, traffic safety, consumer products, personnel justice, consumer finance, and environmental. Different regulatory agencies have created guidelines for these areas of social regulation.

Social regulation of the medical industry was first introduced in 1938 through the Federal Food, Drug, and Cosmetic Act. Premarket approval for a medical device was first required in the late 1960 's. The enactment of 28 bills between 1965 and 1975 culminated with the enactment of the Medical Device Amendments of 1976.

In addition to the medical device industry, six current research studies within regulated industries were reviewed. Research approaches were compared with social and econonic profitability as the focus of the investigations.

\section{Method}

A descriptive-comparative research approach was conducted to examine the relationship and differences between elements of the independent variables, company characteristics and opinions, and the dependent variable, time to equivalence. Descriptive and inferential statistical data, characterizing variable relationships and differences, were obtained through the use of a mailed survey collecting factual and opinion data from a geographically dispersed 
Time to Equivalence population of orthopaedic medical device manufacturers. A researcher-designed questionnaire was used to collect data. A descriptive-comparative approach was used for data analysis.

\section{Collection of Data}

Data sources for the study were small and large orthopaedic medical device manufacturers from all over the U.S. Firms were selected rrom the $510(\mathrm{k})$ Register, which listed all $510(\mathrm{k})$ device submissions from 1976 to 1987 . There were 263 usable responses from firms representing 27 different device categories.

The researcher-designed instrument consisted of a letter of transmittal and a questionnaire composed of three data collection pages with instructions.

After meeting criteria for data sources, steps were taken to implement data collection. The questionnaire was mailed to small and large firms selected from the $510(\mathrm{k})$ Register. Responses to the questions were compiled on an individual basis. A total of 106 questionnaires with self-addressed envelops was mailed. This process resulted in a 238 return rate. Those respondents who did not return the mailed survey initially were then surveyed via the telephone. These two combined techniques produced a total of 39 companies with a 47.58 return rate. 
Time to Equivalence

\section{Analvsis of Data}

Descriptive-comparative statistics were used to answer the research questions. Standard measures of central tendencies comprising means and standard deriations were used to describe relationships and differences between variables. Analyses for the impact of the independent variables upon the dependent variable, time to equivalence, were performed. Comparisons of means related to company characteristics were made. Regression coefficients, beta weights and Rruskal-Wallis chi-square statistics were calculated.

\section{Findings}

Research Question One asked what was the relationship between time devoted to establishing an FDA disposition of substantial equivalence for an orthopaedic medical device and related costs and resource consumption.

Hypothesis 1.1. The first independent variable was the number of years a company had been manufacturing medical devices. This impact was in a negative direction. A statistically significant difference was detected at the 0.05 level. A relationship was found to exist between the number of years manufacturing and time to equivalence. As the number of years a company manufactured medical devices increased, there was a predictable decrease in the amount of time required to get a medical device through the FDA review process and establish equivalence. 
Time to Equivalence

Hypothesis 1.2. The second independent variable was the number of employees in the organization. The relationship of this variable with time to equivalence was evaluated over time from 1977 to 1987. Positive relationships were found to exist from 1978 through 1982 . As the number of employees in a company increased, so did the number of days required to establish equivalence during these years.

A statistically significant difference was ascertained at the 0.05 level from 1978 through 1982, while no predicable relationship seemed to exist in 1977, nor from 1983 through 1987.

A rationale for this result may be found in the combined response of FDA and industry to the enactment of the 1976 Medical Device Amendments. Fhe years immediately following the enactment brought about many changes in personnel and resource consumption for both the agency and industry. As years passed the FDA review process became more competent and sophisticated. Companies employed increasingly more professionals to meet the increased FDA compliance stipulations. However, companies discovered that saturated departments were not producing reduced time to equivalence.

Hypothesis 1.3. The third independent variable was number of employees in the regulatory department. This relationship was also evaluated over time. īo statistically significant difference was achieved for any year from 1977 through 1987. Although no statistically significant difference was apparent, the number of 
Time to Equivalence

employees in the regulatory department did seem to have a negative impact on time to equivalence.

Research Question Two asked if there were any differences between respondents (companies) who possess or do not possess certain identified characteristics and time required to establish equivalence.

Bypothesis 2.1. For the first independent variable, class of device based on the associated degree of risk, the chi-square statistic of 0.224 was not statistically significant at the 0.05 level. In other words, time to equivalence seemed to be independent of the class of device manufactured.

Hypothesis 2.2. For the second independent variable, in-house regulatory department, the chi-square statistic of 4.11 was found to be statistically significant at the 0.05 level in 1979 oniy. Time to equivalence was impacted by the presence of an in-house regulatory department in 1979, but not from 1977 through 1978, nor from 1980 through 1987.

Hypothesis 2.3. The third independent variable, regulatory training, was found to impact time to equivalence in 1979 and 1980 only. The chi-square statistic of 7.04 in 1979 and 1980 revealed a statistically measurable difference in time to equivalence for these years, but not from 1977-1978, nor 1981 through 1987. Thus, those companies who received regulatory training in 1979 and 1980 were found to have a difference in time to equivalence at the 0.05 significance level as compared to companies who did not experience

Page 121 


\section{Time to Equivalence}

regulatory training in 1979 and 1980.

Eypothesis 2.4. The fourth independent variable, number of medical devices manufactured, influenced time to equivaíence for all years except 1984 and 1986. The chi-square statistic detected a statistically measurable difference at the 0.05 level in time to equivalence for all years but 1984 and 1986. The chi-square statistic of 11.60 from 1977 through 1979 was noteworthy. Aside from 1984 and 1986, companies who manufactured more than one device required notably fewer days to establish equivalence than companies that manufactured only one device.

Hypothesis 2.5. For the fifth independent variable, use of an outside reguiatory consultant had a statistically significant impact on time to equivalence from 1977 through 1979, and then again in 1984. No difference was detected from 1980 through 1983 , nor after 1984. The chi-square statistic for 1977 (5.17), 1978 $(6.02), 1979(7.18)$ and 1983 (4.47) was statistically significant at the 0.05 level. Time to equivalence seemed to be dependent on outside consultant use for these years alone.

Research Question Three asked if there were any differences between time to equivalence and respondent's (company's) attitudes about selected characteristics of the regulatory process as having an impact on time to equivalence.

Hypothesis 3.1. The first independent variable, written communication with FDA, was measured. The chi-square statistic of 15.67 was statistically significant at the 0.003 level indicating

Page 122 
Time to Equivalence

that those respondents who agreed with the tenet that written communication with the FDA has an impact on time to equivalence had a significantly lower mean days to equivalence than those that disagreed with this position.

Hypothesis 3.2. The second independent variable, oral communication with FDA, was evaluated. No statistically significant difference was detected in mean responses to this variable. The number of days required to get a device through the FDA review process seemed to be independent of respondents' opinions about oral communication with FDA.

Hypothesis 3.3. The third independent variable, opinions about regulatory training, was evaluated with regard to time to equivalence. The difference in mean days to equivalence for respondents who agreed or did not agree that regulatory training impacted time to equivalence was not statistically significant.

Hypothesis 3.4. The fourth independent variable, opinions about the presence of an in-house regulatory department and its impact on the FDA review process, was evaluated. No statistically significant difference at the 0.05 level in mean days to equivalence was detected betwecñ the classes of agreement, although the vast majority of the respondents agreed that time to equivalence was impacted by the presence of an in-house reguiatory department.

Bypothesis 3.5. The fifth independent variable, opinions about regulatory consultant use and its impact on time to equivalence, 
Time to Equivalence

mas measured. The chi-square statistic of 11.25 was statistically significant at the 0.024 level of significance. This would seem to suggest that those respondents who agreed with the tenet that consultant use impacts time to equivalence had a statistically measurable difference in mean days to equivalence from those that did not agree. Those respondents who agreed had lower mean days to equivalence than those who did not agree.

Question Number Four asked what combination of independent variable measures best predicted time to equivalence.

Multiple regression prediction converted beta weights were statistically sigrificant at the 0.05 level for opinions about oral communication with FDA and opinions about use of outside regulatory consultants. Thus, as opinions about oral communication with FDA and its impact on time to equivalence shifted from agreeing to disagreeing, there was a corresponding increase in days to equivalence. And, as opinions about outside consultant use and its impact on time to equivalence shifted from agreeing to disagreeing, there was a predictable increase in days to equivalence.

Question Number Five asked what variables appeared to have an impact on time to equivalence as perceived by the company respondent.

Eighty one percent $(n=213)$ of the respondents provided additional entities which they thought impacted the time required to get a medical device through the review process and onto the market. Sixteen general categories were referenced by the 
Time to Equivalence

respondents. The respondents noted changing regulations as impacting time to equivalence most often (268). The bulk of the other comments were represented by the following categories: changing FDA policy, lawyers and FDA review panel, limited FDA staff, and properly prepared submissions.

\section{Conclusions}

This section discusses conclusions drawn from the findings, relates them to prior research, and presents implications of the findings regarding business and government. The research addressed the relationship of federal social regulations and the time required to get an orthopaedic medical device through the FDA review process and onto the market for commercial distribution. Financial profit and performance of medical device firms, measured by time to equivalence, was generally impacted by some, but not all, company characteristics in conjunction with federal social regulations. The degree of influence was tempered by circumstances surrounding the industry and the agency at the time of the evaluation. As the 1976 Amendments unfolded in the first few years, both industry and federal agency influenced time to equivalence. This dynamic pericd had general positive and negative effects on time to equivalence. When company characteristics were examined separately over time, specific positive and negative influences could be perceived. 
Time to Equivalence

of the three variables relating costs and resource consumption to time to equivalence, the number or̈ years a company manufactured medical devices tended to negatively influence time to equivalence the greatest. The number of employees in the organization increased time to equivalence during the early years of the amendment enactment, but had little effect in the later years. The number of employees in the regulatory department had very iittle influence on time to equivalence, although a gradual decline in time to equivalence was seen year after year with regard to this variable.

of the five identified company characteristics proposed to have an influence on time to equivalence, companies that. manufactured more than one device had the most consistent difference in mean days to equivalence over time. The type of device a company manufactured had little impact on time to equivalence. The presence of an in-house regulatory department had some influence on the mean days to equivalence, but this was in the years just after the enactment of the 1976 amendment. Regulatory compliance training also had an impact on time to equivalence, but this was only observed in 1979 and 1980 when federal guidelines related to the 1976 amendment were being better explicated and interpreted by both industry and agency. Use of regulatory consultants impacted time to equivalence, but only in selected years. In the early years after the 1976 amendment enactment when the guidelines were least understood and most difficult to implement, consultant use was highest and seemed to have the 
Time to Equivalence greatest influence on time to equivalence. Then again in 1984, when new, additional guidelines were issued, consultant use appeared to produce a difference in mean days to equivalence.

of the five selected respondents' (companys') attitudes about specified characteristics of the regulatory process, the different classes of agreement regarding written communication with FDA and use of out-of-house consultants were most dissimilar. The data were generally sufficient to indicate a difference in mean time among the different categories of agreement. The respondents' different categories of opinion with respect oral communication with FDA, regulatory compliance training, and the existence of an in-house regulatory department were not apparently different as they related to mean days to equivalence.

The variability of relative prediction estimates was great for the twelve combined independent variables. Opinions about use of outside consultants and oral communication with FDA best predicted time to equivalence. A relationship was seen to exist between these variables and time to equivalence. Based on the classification system, opinions which favored consultant use and oral communication with the FDA also corresponded with a decrease in time to equivalence. However, the aggregation of data as to what the combined effect these seiected independent variables had on time to equivalence was difficult to determine.

Financial profits and performance are vital elements in the success of the business operation. As such, the influence of social 
Time to Equivalence

regulation upon financial profits and performance has an important impact in this area. Conclusions that there exists a clear relationship between business and government, that the relationship sometimes benefits business operations, and at other times hinders the growth of the business, can be applied to social regulation as well.

While realizing that positive, negative, and no influence relationships exist, a general statement on the impact of regulations and company characteristics on time to equivalence can be drawn from the research findings. The conclusion is that the general impact of social regulation and selected company characteristics upon time to equivalence for small and large orthopaedic medical device manufacturers is negative at a minor level.

of the many arguments in the literature favoring social responsibility, the most prevalent was that of the long-run selfinterest of business. This concept rationalizes that society expects business to be aware and consider the needs and goals of society in the internal decision process if business expects to profit in the long run. The argument is actually a sophisticated concept of long-run profit maximization, i.e., spending money to comply with socially imposed guidelines will result in more profit for business. Assuming that decreased time to equivalence results in reduced compliance costs, the literature by Ford (1969) and the tentative results of prior studies suggesting that socially 
Time to Equivalence responsible firms may be more profitable were supported by the present study.

\section{Implications for Business and Government}

The development of social regulations in American business has been brought about by both external and internal events. External causes have been largely legislative in nature.

Federal social regulations, through their impact upon profit and performance of small and large firms, have impact of great significance upon business and government decision making and policy formation in general. A management philosophy which includes both pragmatic and idealistic aspects often presents management with a troublesome dilemma. On the one side, business management must pursue economic objectives; on the other, they must indertake social objectives. Management must attempt to resolve this dilemma.

In support of economic objectives, if a business firm fails to make a profit, the firm will not survive. Should this happen, the firm will be in no position to assume social objectives. However, this is an extremely polar view of the dilemma. In reality, it is not so easy to separate economic objectives from social ones.

Understanding the particular impacts to be expected from social regulations and how they relate to financial profit and performance is crucial to private enterprise in their internal decision making regarding the policy and strategy formulation of 
Time to Equivalence their overall business operation. A major implication in preceding studies was the possibility of a business-government coalition. It is essential for the government sector to understand and take into account the impact of their decision making and imposition of regulations. To effectively weigh costs and benefits of legislation requires knowledge of its impact. This has implications for medical device manufacturers and regulatory consultants. The ability to determine when to implement the expertise of a regulatory consultant or expand a regulatory department may have dramatic results on market emergence. This study suggests that regulatory expertise should be sought within the first two years of new regulation enactment since the effects of compliance related activities are most dramatic during this period. It should also be emphasized that a regulatory consultant or regulatory department encompass many individuals with varied expertise. The consultive team of physicians, statisticians, nurses, and lawyers in concert with the reguiatory professional is needed to truly effect time to equivalence within the medical device industry.

Attempts to stimulate the economy through an increase in financial profit and performance must take into account current policies that work as restraints. The study identified major company characteristics which interact with these restraints which impact operations of orthopaedic medical device firms.

Social regulations do open up certaiñ opportunities of which companies can take advantage. The varied impact of social 
Time to Equivalence regulations in relation to orthopaedic medical devices indicates the complexity of the impact structure and negates efforts to formulate effective broad-based regulatory legislation.

Firms which fail to recognize the importance of social issues and drag their feet on positive action or attempt to side step federally sanctioned guidelines are facing not only public and government action, but, more importantly, severe delays in entering a very competitive market. Battle lines are drawn and the chailenge is clear. Only the future can tell what the outcome will be.

The results of this specific study suggested that medical device manufacturers and possibly other similar companies may negatively influence the time required by FDA to review a 510(k) submission by doing the following:

1) Engage regulatory professional consultants when new regulations which are difficult to interpret by in-house personnel are introduced or when repeated deficiency letters are returned from FDA.

2) Expect your regulatory affairs consultant to be an expert in clinical protocol and designs monitoring.

3) If training provided by sanctioned regulatory bodies is not satisfactory, engage consultants to provide training to company personnel in new developments in procedures which are sensitive to your medical device.

4) Increase the scientific soundness of the submissions since FDA is continually increasing its regulatory 
Time to Equivalence

requirements.

5) Communicate, both orally and in writing, with FDA when device configuration or indication changes are introduced.

6) New companies within the medical device industry should make early investments in regulatory expertise since time to equivalence declines with an increase in experience (i.e., number of years manufacturing) and a diversification of product (i.e., number of devices manufactured)

7) In the future, possibly consider industry self-regulation with minimal FDA oversight.

\section{Recommendations for Future Research}

This was a descriptive-comparative study which evaluated the impact of social regulations in conjunction with selected company characteristics on orthopaedic medical device manufacturer's ability to reduce the time to reach substantial equivalence with a pre 1976 amendment medical device as determined by FDA reviewers. The study suggested several areas for additional research, concerning many of the same variables and issues. Therefore, several expanded studies were recommended as follows:

1. Expand the current study to include a statistically significant number of medical device firms other than orthopaedic. 
Time to Equivalence

This recommendation was supported by this study's questionabie generalization.

2. Expand the current study to include other company and agency characteristics in the evaluation of a medical device firm's profitability. This was supported by the logical projection of this current study.

3. Expand the current study to include the impact of company characteristics and regulations upon other areas of profitability (i.e., marketing, manufacturing, fiñance, etc.) relevant to gross income. This also appeared to be a natural projection of this study's endeavors.

4. Further research defining and clarifying the impact, particularly positive contributions of regulation, that is needed to assist in effective planning and decision making by business and government. This recommendation was guided by the need for an alternative orientation to evaluating the impact of regulations, since this study was basically negative in perspective.

5. Further research should be done using a larger sample. As with any experimental design and analysis, more confident inferences can be made and conclusions drawn when the study sample more approximates the study population.

6. Expand the study to represent both large and small firms equally and analyzed separately. This also would further generalize the study results.

Page 133 
Time to Equivalence

7. Develop a study to include only class III devices since there are more profitability measures associated with this moxs risk related device.

8. Develop a study which clearly confirms the connection between social regulations and profit and performance. This recommendation was based on the literature supported need for such analysis.

9. Develop a study to educate medical device manufacturers about the most efficient and cost effective paths to regulatory compliance. This recommendation was apparent in view of this study's finding that regulatory training seemed have little impact on time to equivalence.

10. Design a study to develop the reliability and validity of the measurement instrument. This recominendation was based on the need for a more acsurate and standardized data collection vehicle.

Page 134 
Time to Equivalence

REFERENCES

Alexander, G. J. \& Bucholz, R. A. (1978). Corporate social responsibility and stock market performance. Academy of Management Journal, 21, 479-\$86.

Ansoff, H. I., Bosman, A., and Storm. P. M. (Eds.). (1982). Understanding and managing strategic change. Amsterdam: NorthHolland Publishing Co.

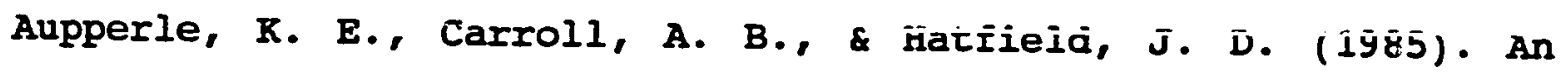
empirical examination of the relationship between corporate social responsibility and profitability. Academy of Management Journal, $\underline{28}(2), 446-463$.

Bagozzi, R. P. (1980) - Causal models in marketing. New York: Wiley.

Borg, R.B. \& Gall, M.D. (1979). Educational research, New York, NY: Longman, Inc.

Boulton, พ. R., Linsay, W. M., Frankiln, S. G., and Rue, W. (1982). Strategic planning: determining the impact of environmental characteristics and uncertainty. scademy of Management Journal, 25, 500-509.

Page 135 
Time to Equivalence

Burgher, P. H. (Ed.). (1979) - Changement - Understanding the management business change. Lexington, Mass: D.C. Heath and co.

Chakravarthy, B. S. (1982). Adaptation: a promieing metaphor for strategic management. Academy of Management Review, I, 3544.

Diogenes. (1988). The $510(\mathrm{k})$ register $(1988$ ed.). Rockville, Maryland: Author.

Drew, G. (1986). Medical devices: a primer on medical device regulation. FDA Consumer, $\underline{5}(24), 24-27$.

Eads, G. C. (1981). Harnessing regulation: the evolving role of the white house oversight. Requlation, 5 , 19-25.

Eusenbeis, R. A. (1981). Regulation and deregulation in banking. Bankers Magazine, $164(2), 25-33$.

Ferber, M. A. and Birnbaum, B. G. (I979). Retrospective earnings data: Some solutions for old problems. Public Opinion Quarterly, 43(1), 112-118.

Page 136 
Time to Equivalence

Perreira, J. (1977). Hechanisms for sharing the costs of large accidents. Washington, DC: National Technical Information Service.

Flaherty, J. E. (1979). Managing change: Today's challenge to management. New York: Nellen Publishing Company, Inc.

Ford, H., II (1969). Business, the environment and the quality of life. A speech delivered befere the Harvard Business School Public Affairs Forum, Boston, MA, December.

Fox, D. (1969). The research process in education. New York: Holt, Rinehart, and winston.

Fritscher, L. A., \& Bernard, R. (1980). Business requlation and government decision making. Cambridge, Massachusetts : Winthrop Publishers.

Gart, A. (1984). The insider's guide to the financial services revolution. New York: McGraw-Hill.

Ginsberg, A. (1984). Operationalizing organizational strategy: Toward an integrative framework. Academy of Management Review, 2. 548-557. 
Time to Equivalence

Ginsberg, A. (1986). Strategic adaptation during a period of industry transition: an empirical investigation of strategic changes among financial depository institutions (Doctoral dissertation, University of Pittsburgh, 1985) - Dissertation Abstracts International, 3058.

Ginsberg, A. and Vankatraman, N. (1985). Contingency perspectives of organizational strategy: A critical review of the empirical literature. Academy of Management Review, 10, 62.2-628).

Gregson, R. A. M. (1975). Psychometrics of similarity. New York: Academic Press.

Greene, J. (1980). Requiatory problems and requlatory reform. New York: McGraw-Hill.

Gup, B. E. and Whitehead, D. D. (1983). Shifting the game plan: Strategic planning in financial institutions. Economic Review of the Federal Reserve of Atlanta. December, 22-23.

Gutek, B. A. (1978). On the accuracy of retrospective attitudinal data. Public opinion Quarterly, 42(3), 390-401.

Heinz, D. C. (1976). Financial correlates of a social measure. Akron Business and Economic Review, I(1), 48-51. 
Time to Equivalence

Holmberg, S. R. and Baker, H. R. (i982). The CEO's role in strategic planning. Journal of Bank Research, 12(4): 218-227.

Huber, G. P. and Power, D. J. (1985). Retrospective reports of strategic-level managers: Guidelines for increasing their accuracy. Strategic Management Journal, $6,171-180$.

Igelhart, J. (1973). Health report/federal regulation of medical devices gets serious attention in congress. National Journal Reports: 8 ; $1184-1188$.

Lachin, J. M., Matts, J. P., \& Wei, L. J. (1988). Randomization in Clinical Trials: Conclusions and recommendations. Controlled Clinical Trials, 2, 365-374.

Lazarsfield, P. and Menzel, H. (1969). On the relationship between individual and collective properties. In A. Etzioni (Ed.) Complex Organizations: A Sociological Reader. New York: Holt, Rinehart and winston, Inc.

Lenz, R. T. (1980). Environment, strategy, organization structure and Performance: Patterns in one industry. Strategic Management Journal, 1, 209-226. 
Time to Equivalence

Yarsh, C. (1982). The survey method: The contribution of surveys to sociological explanation. London: George Allen and Unwin.

McCay, N. I. (1986). Industry effects of medical device regulation: the case of diagnostic imaging equipment. Journal of Policy Analysis and Management, $\underline{6}(1), 35-44$.

McGrath, J. E. (1981). Dilemmatics: The study of research choices and dilemmas. American Behavior Scientist, 25, 179-210.

MCRay, N. L. (1986). Industry effects of medical device regulation: The case of diagnostic imaging equipment. Journal of Policy snalysis and Management, $\underline{6}, 1,35-44$.

Miles, R. H. (In collaboration with R.S. Cameron) ( 1982). Coffin nails and corporate strategies. Englewood Cliffs, N.J.: Prentice Hall.

Miller, D. and Friesen, P. H. (1982). The longitudinal analysis of organizations: A methodological perspective. Management Science, 28, 1013-1034.

Miller, J. C. and Yandle, B. (1979). Benefit-cost analysis of social regulation. Washington,DC: American Enterprise Institute for Public Policy Research. 
Time to Equivalence

Moss, L. and Goldstein, H. (1979). The recall method in social surveys. London: University of London Institute of Education.

Murray, R. B., \& Montanari, J. R. (1986). Strategic management of the socially respcrsible firm: integrating management and marketing theory. Academy of Management Review, 11(4), 815827 .

Nicholson, E. A., Litschert, R. J. \& Anthony, W. P. (1974). Business responsibility and social issues. Columbus, Ohio: Charles E. Merrill Publishing Company.

Office of Device Evaluation, Center for Devices and Radiological Health, Food and Drug Administration, Annual Report - Fiscal Year 1988, 38 (Nov. 1988).

Parker, G. C. (1981). How management wili make or break the bank. Harvard Business Review, $\underline{59}(6), 140-148$.

Parket, R. \& Eilbert, H. (1975). Social responsibility: The underlying fācicors. Business Forizons, $18(4), 4-10$.

Phillips, J. R. (1983) . Enhancing the effectiveness of organizational change management. Human Resource Management, 22. 183-199.

Page 141 
Time to Equivalence

Powers, E. A., Goudy, W. J., \& Reith, P. M. (1978). Congruence between panel and recall data in longitudinal research. public Opinion Quarterly, $\underline{42(3), 380-389 .}$

Public Law No. 94-295, 4(a)(9) Stat. 540, 580 (1976) (codified at 21 U.S.C $360(k)(1982)$.

Public Law No. 75-717, 52 Stat. 1040 (1938), as amended 21 U.S.C. 301-392.

Resnick, B. P. (1985). Corporate training in climates of critical adjustment: a case study of the airline industry under government deregulation, 1978-84. Dissertation Abstracts International, 46, 3058 .

Rogowski, R. J. (1984). The small players in the financial service game. The Bankers Magazine, Nov-Dec., 59-63.

Smith, A. (1937) An inquiry into the nature and causes of wealth of nations (1776). New York: Modern Isibrary, Inc.

Smith, R. A. (1981). Instead of regulation: alternatives to federal regulatory agencies. Robert W. Poole, Jr., Ed., Lexington, MA: Lexingcon Books.

Page 142 
Time to Equivalence

Sfeir, G. \& Renger, C. (1987). Big future seen for regulatory professionals. RAPS News, July/August, $1-4$.

Sturdivant, F. D. and Ginter, J. I. (1977). Corporate social responsiveness. California Management Review, 19(3), 30-39.

Swanson, M. (1974). The monetary process: essentials of money and banking. Eoston, MA: Houghton-Mifflin Company.

Toffler, A. (1984). The adaptive corporation. New York: McGrawHill.

Ungson, G. R., James, C., \& Spicer, B. H. The effects of regulatory agencies on organizations in wood products and high technology/electronics industries. Academy of Management Journal, $\underline{28}(2), 426-445$.

U. S., (1983) - Federal Register, 48:40272, Sept. 6 .

U.S., (1987). Federal Register, 21:888, Sept. 4 .

U.S. Congress, House Committee on Interstate and Foreign Commerce. (1973). Medical Devices, hearing before the Subcommittee on Public Health and the Environment, Oct. 23-24, serial No. 9361 (Washington, DC: U.S. Government Printing Office, 1973). 
Time to Equivalence

U.S. Congress, House of Representatives. (1976). The medical device amendments of 1976 . $94^{\text {th }}$ Cong., 2nd sess. House Report No. 94853 (Washington, DC: U.S. Government Printing Office, 1976)

U.S. Council on Environmental Quality. 1979. Tenth Annual Report. Washington, DC: U.S. Government Printing Office.

Weick, K. E. (1969) - The social paychoiogy of organizing. Reading, Mass : Addison-Wesley.

Weidenbaum, M. I. and De Fina, R. (1978). The cost of faderal regulation. Washington, DC: American Enterprise Institute. 


\section{APPENDIX A}

Director, Regulatory Department

P.O. Box 988

U.S. Highway 30 East

Warsaw, IN 46580

Dear Director,

In confunction with the University of San Diego, I am conducting research in the field of regulatory affairs and medical devices. Part of the initial stages of the research requires a pilot study. Its purpose is to assess the viability and feasibility of the proposed study. One of the main tasks of this pilot is the assessment of the data collection form or questionnaire.

Please find enclosed a copy of the questionnaire that will be mailed to approximately 250 regulatory affairs managers such as yourself. These managers will be from throughout tise U.S. Along with the questionnaire, the regulatory affairs manager will receive a cover letter explaining the research project. You have a copy of this as well.

I fully appreciate your very busy schedule, but your assistance is needed in the validation process of this questionnaire. Would you take 20-30 minutes to review the enclosed cover letter and questionnaire? Some of the areas which I would like you to address are: 1) Is the questionnaire realistic? 2) Will managers fill it out? 3) Do the questions address the issue of compliance 4) Are there guestions get a device through the $510(\mathrm{k})$ process? Does the cover luestions which might compromise the company? 5) would help secr letter invoke a feeling of cooperation which whe participation of the manager in the study?

Your comments are essential to the success of this project. questionnaire. Once finished directly on the cover letter and self addressed

A preliminary publishing agreement has been reached with a and contributions in the results of this study. Your comments relevant.

project that much more

Thank you for your time and cocperation. Eopefully, our efforts

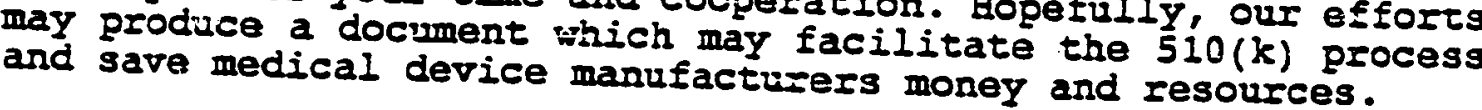

Sincerely,

John J. Carlow

Director, Clinical statistics

JJC/mdg

Page 145 


\title{
APPENDIX B
}

\author{
Supervisor - Clinical/Regulatory Affair \\ 3M Center 270-5N-05 \\ St, Paul, MN 55144
}

Jear Ms. Danielson,

Research is being conducted on the impact of government regulations upon the time required to get an orthopaedic medical device through the FDA review process and onto the market. Your firm was selected through publication of the $510(\mathrm{k})$ Register. You met the selection criteria because $\bar{y}$ tur cowpany has had at least one product approved (k) proces $=$ between the years 1977-1987.

The key role you have in your firm's success makes your view and counsel of extreme value. Hould you please contribute to this research by completing the enclosed questionnaire.

The questionnaire is designed to obtain specific information about your company. In addition, your opinion on the impact of federal regulation upon your firm's ability to successfuliy progress through the premarket notification process is also being requested.

Recognizing your demanding schedule, the form was designed to be questionnaire, you desire a summati. If, after completing the please indicate so on the fommary copy of the research results, in MaY, 1990.

If you so choose, you do not have to participate in this research questionnaire, you are choose to participate by completing the may be compromising to you or youred to answer questions you feel The information you contribute to this research will remain
confidential and be used only to support this study.

It is essential that your response be received by September, 1989. Tour contribution, by completing the enclosed questionnaire, wili add immensely to the knowledge in this area.

Thask you for your time and interest.

Sincerely,

Johr J. Carlow,

Researcher

Enclosures 


\section{APPENDIX C \\ SURVEY QUESTIONALIRE}

1.0 Please indicate the year your company started manufacturing
medical devices?

2.0 Please supply the following information as it relates to the yearly intezrals in the left column. If your company was not leave that section incomplete during certain yearly intervals,
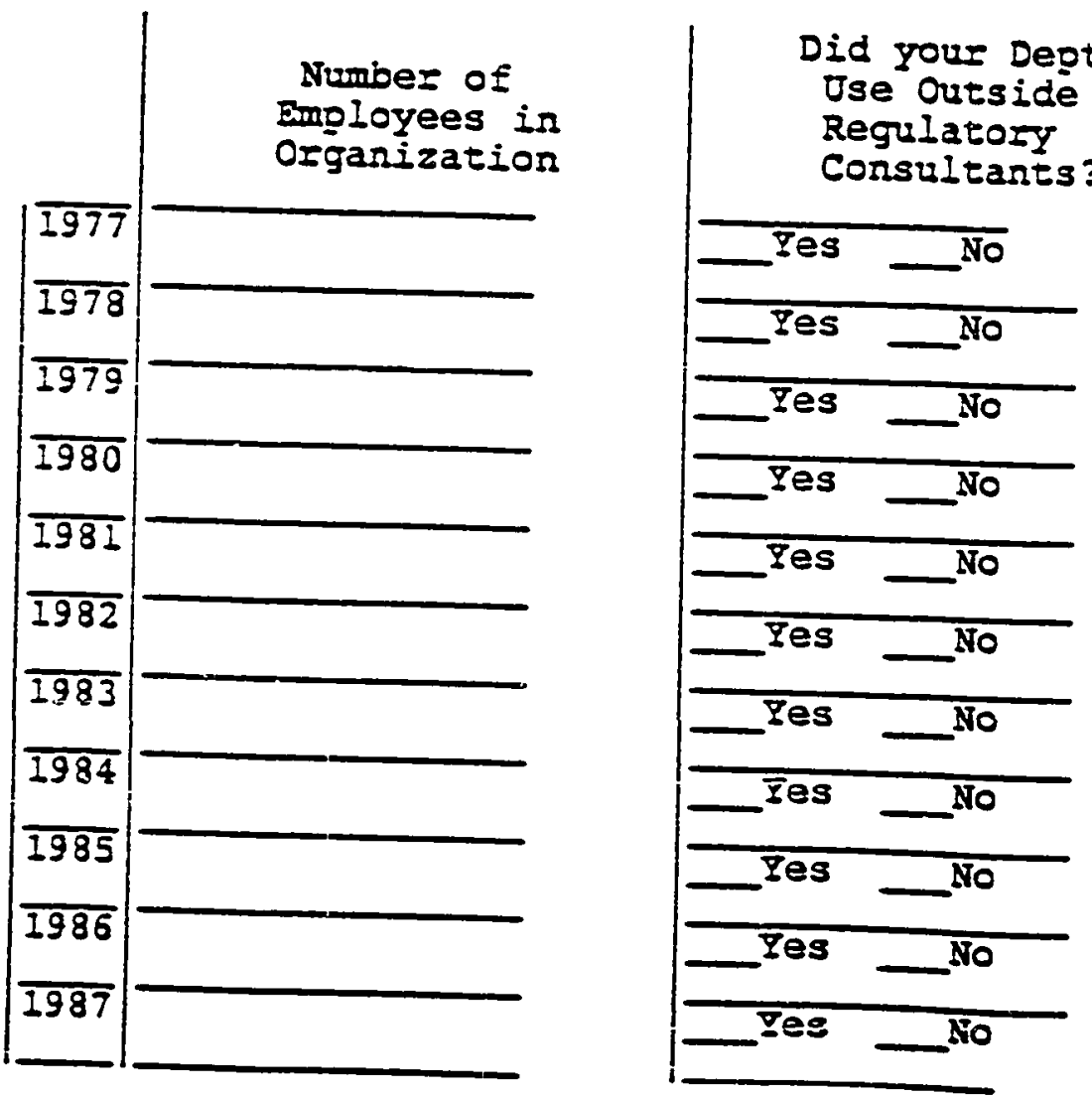


\section{APPENDIX C (CORTinued)}

3.0 Please supply the following information as it relates to the
yearly interval in the left column.

\begin{tabular}{|c|c|c|}
\hline & $\begin{array}{l}\text { Tere you Manufacturing } \\
\text { Yore than One Device }\end{array}$ & $\begin{array}{l}\text { Did your Department } \\
\text { Receive Regulatory } \\
\text { Training of any Kind }\end{array}$ \\
\hline$\overline{1977}$ & Yes & Yes _no \\
\hline$\overline{1978}$ & 工es _ & Ye3 \\
\hline$\overline{1979}$ & Pes & Yes \\
\hline$\overline{1980}$ & Zies _No & Tres _No \\
\hline$\overline{1981}$ & Yes _No & Yes \\
\hline$\overline{1982}$ & Yes & Zes $^{\text {No }}$ \\
\hline$\overline{1983}$ & Yes _No & Yes \\
\hline 1984 & Fes & Yes ${ }^{\text {NO }}$ \\
\hline$\overline{1985}$ & Yes & Fes \\
\hline$\overline{1986}$ & Fes $^{\text {No }}$ & Fes $^{\text {No }}$ \\
\hline 1987 & Tes & Zes $^{\text {No }}$ \\
\hline
\end{tabular}

4.0 In your opinion, are production costs influenced by the time

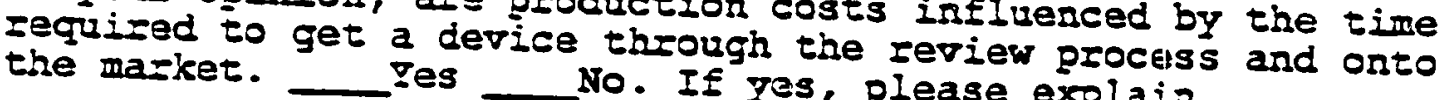
No. If yes, please explaia 


\section{APPENDIX $\subseteq$ (continued)}

Please indicate your PERCEPTION of the kind of influence the Eollowing events or situations have PRESENTLY on the time that is needed to get a product through the FDA Ieview orocess and to the market. Circle the appropriate category that describes your perception for questions 4 through 8 below.

4.0 Written Communication beyond the submission with the FDA resuIts in decreased time to get a product through the FDA review process
and on the market.

\begin{tabular}{|c|c|c|c|}
\hline $\begin{array}{l}\text { Stzongly } \\
\text { Agree }\end{array}$ & Agree & $\begin{array}{l}\text { No } \\
\text { Opinion }\end{array}$ & Disagree \\
\hline
\end{tabular}

5.0 Oral Communication with the FDA results in decreased time to get a product through the FDA Ieview process and on the market.

\begin{tabular}{|c|c|c|c|c|}
\hline $\begin{array}{l}\text { Sirongly } \\
\text { Agree }\end{array}$ & Agree & $\begin{array}{l}\text { No } \\
\text { Opinior }\end{array}$ & Disagree & $\begin{array}{l}\text { Stzongly } \\
\text { Disagree }\end{array}$ \\
\hline
\end{tabular}
6.0 Reculatorg Affairs Training results in decreased time to get $a$
Strongly
Agree
Agree
No Disagiee
Opinion
Strongly
Disagree

7.0 An In-house Reculatory Affairs pepartment results in decreased time to get a product through the FDA Ieview process and on the
market.

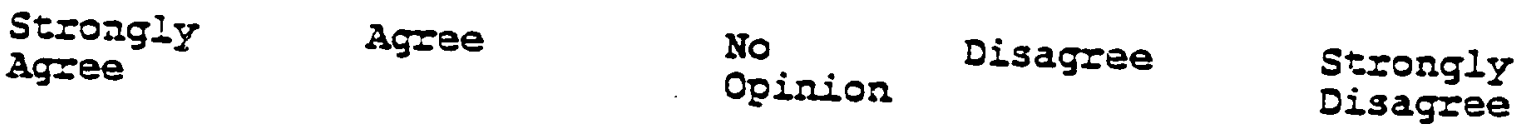

8.0 Use of Qutside Regulatory Rffairs Consultants results in decreased time to get a product through the FDA Ieview process and on the
Strongly
Agree
No Disagree
Opision
Strongly
Agree
Disagree 9.0 In your opinion, are tisce other things which impact the time to
get a product through the seview process and onto the market?

If you want the results of this research forwarded

indicate by checking the appropriate category.

to you, please Tes No 


\section{APPENDIX D}

Summary of Research Eypotheses Regarding

the Relationship Between Organizarional Characteristics and Time to Established Equivalence

\begin{tabular}{|c|c|c|c|}
\hline & \multicolumn{2}{|c|}{ RBIATIONSEIP } & \multirow[b]{2}{*}{$\begin{array}{l}\text { Expected Direction } \\
\text { of the Relationship }\end{array}$} \\
\hline $\begin{array}{l}\text { Eypothesis } \\
\text { Number }\end{array}$ & $\begin{array}{l}\text { Dependent } \\
\text { Variable }\end{array}$ & $\begin{array}{l}\text { Independent } \\
\text { Tasiable }\end{array}$ & \\
\hline 1.1 & $\begin{array}{l}\text { Time (days) to } \\
\text { Equivalence. }\end{array}$ & $\begin{array}{l}\text { Number of Years } \\
\text { manufacturing } \\
\text { Medical Devices }\end{array}$ & Negative \\
\hline 1.2 & $\begin{array}{l}\text { Pine (days) to } \\
\text { Equivalence. }\end{array}$ & $\begin{array}{l}\text { Number of } \\
\text { Employees in } \\
\text { Staganization }\end{array}$ & Niegative \\
\hline 1.3 & $\begin{array}{l}\text { Tine (days) to } \\
\text { Equivalence. }\end{array}$ & $\begin{array}{l}\text { Number of } \\
\text { Employees in } \\
\text { Regulatory } \\
\text { Department }\end{array}$ & Negative \\
\hline
\end{tabular}




\section{APPENDIX E}

Summary of Research Bypotheses Regarding

The Difference Between Company Chattacteristics and Timely Compliance

\begin{tabular}{|c|c|c|c|}
\hline \multirow[b]{2}{*}{$\begin{array}{c}\text { Eypothesis } \\
\text { Number }\end{array}$} & \multicolumn{2}{|c|}{ COMPARISON } & \multirow[b]{2}{*}{$\begin{array}{l}\text { Signisicance } \\
\text { Level }=0.05\end{array}$} \\
\hline & $\begin{array}{l}\text { Dependent } \\
\text { Vafiable }\end{array}$ & $\begin{array}{l}\text { Independent } \\
\text { Vasiable }\end{array}$ & \\
\hline 2.1 & $\begin{array}{l}\text { Time (days) to } \\
\text { Equivalence. }\end{array}$ & $\begin{array}{c}\text { Type of } \\
\text { Device } \\
\text { Manufactured }\end{array}$ & $\begin{array}{l}\text { Significance } \\
\text { Level }=0.05\end{array}$ \\
\hline 2.2 & $\begin{array}{l}\text { Time (days) to } \\
\text { Equivalence. }\end{array}$ & $\begin{array}{l}\text { In-Zouse } \\
\text { Regulatory } \\
\text { Depa-tment }\end{array}$ & $\begin{array}{l}\text { Significance } \\
\text { Lerel }=0.05\end{array}$ \\
\hline 2.3 & $\begin{array}{l}\text { Time (days) to } \\
\text { Equivalence. }\end{array}$ & $\begin{array}{l}\text { Regulatory } \\
\text { Compliance } \\
\text { TIaining }\end{array}$ & $\begin{array}{l}\text { Significance } \\
\text { Level }=0.05\end{array}$ \\
\hline 2.4 & $\begin{array}{l}\text { Time (days) to } \\
\text { Equivalence. }\end{array}$ & $\begin{array}{c}\text { Number of } \\
\text { Devices } \\
\text { Manufactured }\end{array}$ & $\begin{array}{l}\text { Significance } \\
\text { Level }=0.05\end{array}$ \\
\hline 2.5 & $\begin{array}{l}\text { Tine (days) to } \\
\text { aquitraience. }\end{array}$ & $\begin{array}{c}\text { Jse of Outside } \\
\text { Regulatory } \\
\text { Consultants }\end{array}$ & $\begin{array}{l}\text { Sigrificance } \\
\text { Lerel }=0.05\end{array}$ \\
\hline
\end{tabular}




\section{APPENDIZ $F$}

Sumary of Research Hypotheses Regarding

Differences in Top Executives Perceived Influences

on Timely Compliance and Time to Equivalence

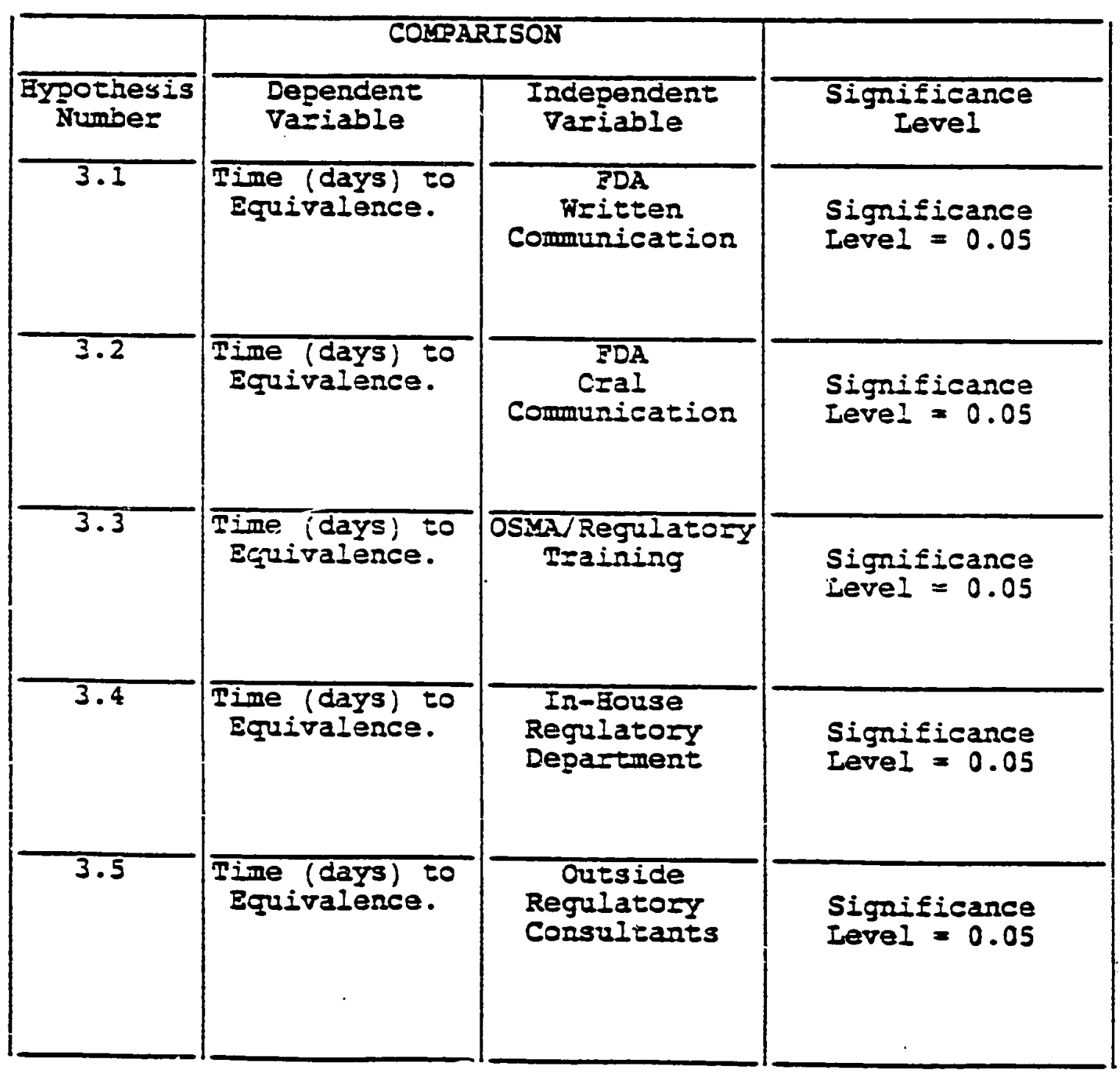

